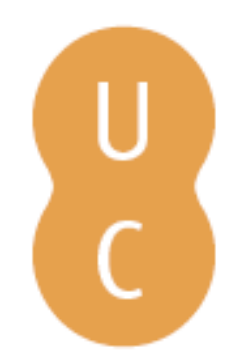

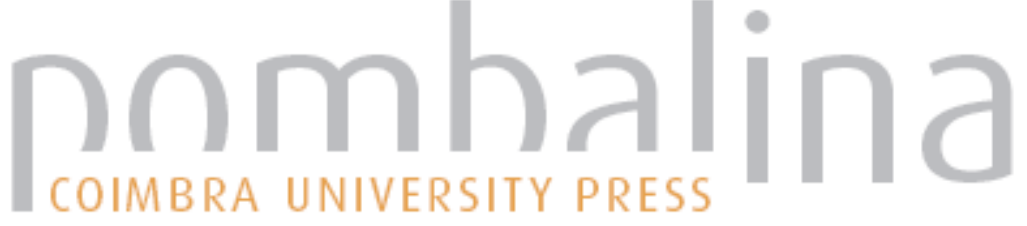

\section{A noção de numerus no De re aedificatoria}

Autor(es): $\quad$ Krüger, Mário; Ferreira, Maria da Conceição Rodrigues

Publicado por: Imprensa da Universidade de Coimbra

URL

persistente: URI:http://hdl.handle.net/10316.2/36678

DOI: $\quad$ DOI:http://dx.doi.org/10.14195/978-989-26-1015-3_16

Accessed : $\quad$ 26-Apr-2023 11:28:41

A navegação consulta e descarregamento dos títulos inseridos nas Bibliotecas Digitais UC Digitalis, UC Pombalina e UC Impactum, pressupõem a aceitação plena e sem reservas dos Termos e Condições de Uso destas Bibliotecas Digitais, disponíveis em https://digitalis.uc.pt/pt-pt/termos.

Conforme exposto nos referidos Termos e Condições de Uso, o descarregamento de títulos de acesso restrito requer uma licença válida de autorização devendo o utilizador aceder ao(s) documento(s) a partir de um endereço de IP da instituição detentora da supramencionada licença.

Ao utilizador é apenas permitido o descarregamento para uso pessoal, pelo que o emprego do(s) título(s) descarregado(s) para outro fim, designadamente comercial, carece de autorização do respetivo autor ou editor da obra.

Na medida em que todas as obras da UC Digitalis se encontram protegidas pelo Código do Direito de Autor e Direitos Conexos e demais legislação aplicável, toda a cópia, parcial ou total, deste documento, nos casos em que é legalmente admitida, deverá conter ou fazer-se acompanhar por este aviso. 
IMPRENSA DA

UNIVERSIDADE

DE COIMBRA

COIMBRA

UNIVERSITY

PRESS

\section{NA GÉNESE DAS RACIONALIDADES MODERNAS II}

Em torno de Alberti e do Humanismo

MÁRIO KRÜGER et alii

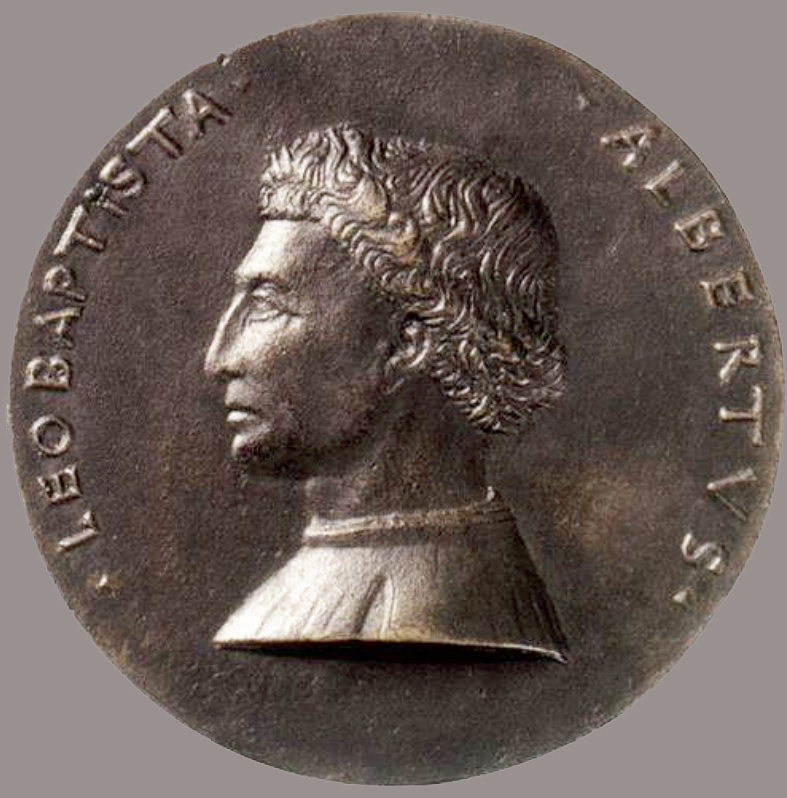




\section{A NOÇ ÃO DE NUMERUS NO \\ DE RE AEDIFICATORIA}

Mário Krüger Maria da Conceição Rodrigues Ferreira

\section{Resumo}

O numerus é uma das principais noções, a par da finitio e da collocatio, em que se condensa a conformidade e a aliança de todas as partes do conjunto a que pertencem, isto, é da concinnitas.

Os numerais para Alberti não apresentam uma dimensão exclusivamente quantitativa, mas também qualificativa, onde é atribuída uma qualidade aos números pares e impares, do ternário até, em relação aos primeiros, ao número dez e, em relação aos segundos, até ao número nove. Os fundamentos das relações de base musical propostos por Alberti não se resumem aos números inteiros, mas são extensíveis às correspondências inatas, hoje designadas de números irracionais, bem como aos números perfeitos 6 e 10, admitidos como tal pelos autores da antiguidade clássica, nomeadamente nos trabalhos de Aristóteles e Euclides, mas ainda passíveis de serem detetados nos levantamentos das suas obras construídas.

Em resumo, Alberti refere-se implicitamente aos números poligonais e explicitamente aos números harmónicos, perfeitos e às correspondências inatas, que são classificados não hierarquicamente e se apresentam com rationes seriadas, com termos ordenados, além de mostrarem simultaneamente dimensões quantitativas, qualitativas, bem como relacionais. 
Esta plasticidade nas possíveis utilizações do conceito de numerus permite a sucessiva requalificação dos sistemas numéricos utilizados na conceção e no projeto edificatório, como um contínuo processo de reflexão em ação, conforme é assinalado por Alberti no tratado. Leon Battista Alberti; De re aedificatoria; Numerus; Sistemas Pitagóricos; Conversões Decimais; Convergências Racionais.

\section{Résumé}

Le numerus est l'une des notions clés, aux côtés de finitio et collocatio, où se condense l'engagement de toutes les parties de la série à laquelle ils appartiennent, c'est à dire de la concinnitas. Cependant, les chiffres pour Alberti ont une dimension non seulement quantitative mais aussi de qualification où une qualité est attribuée à nombres pairs et impairs, jusqu'à nombre dix, pour le premier cas, et jusqu'à nombre neuf pour l'autre.

Ces relations ne se limitent pas à nombres entiers, mais des correspondances innées, aujourd'hui appelé nombres irrationnels, et aussi les nombres parfaits 6 et 10, admis comme tel par les auteurs de l'Antiquité classique, en particulier dans les œuvres d'Aristote et d'Euclide, mais encore capable d'être détecté dans les sondages de leurs œuvres construites.

En résumé, Alberti se réfère implicitement à nombres polygonaux, harmoniques, parfaits et des correspondances innées, qui ne sont pas classés hiérarchiquement, mais avec des rationes présentées en série et des termes ordonnés simultanément par ses dimensions: quantitatives, qualitatives, et enfin, relationnelles.

Cette plasticité dans les utilisations possibles de la notion de $n u$ merus permet le reclassement ultérieur des systèmes numériques utilisés dans la conception et projet des édifices comme un processus continu de réflexion dans l'action, comme le montre Alberti dans le traité.

Leon Battista Alberti; De re aedificatoria; Numerus; Systèmes De Pythagore; Conversions Décimales; Convergence Rationnelle. 


\section{Abstract}

The numerus is one of the main notions, along with finitio and collocatio, that condenses the harmony of all parts to the set they belong, i.e. to concinnitas.

The numerals for Alberti do not have a purely quantitative dimension but also a qualifying one, where quality is assigned to odd and even numbers, up to the number ten, in relation to the former ones and, for the latter ones, up to the number nine.

These are the foundations of musical rationes based on relations proposed by Alberti which are not limited to integers, but are extensible to innate correspondences, called today irrational numbers, and also to perfect numbers 6 and 10, accepted as such by authors of classical antiquity, particularly in the works of Aristotle and Euclid, and still likely to be found in surveys of his built works. In short, Alberti implicitly refers to polygonal numbers and explicitly to harmonic and perfect numbers and innate correspondences, which are not classified hierarchically, but present serial rationes, with ordered terms and also simultaneously display the following dimensions: quantitative, qualitative and, at last, relational dimensions. This plasticity in the possible uses of numerus concept allows the subsequent reclassification of number systems used in the design and project of buildings as an ongoing process of reflection in action, as is shown by Alberti in the treatise.

Leon Battista Alberti; De re aedificatoria; Numerus; Pythagoric Systems; Decimal Conversions; Rational Convergences. 


\section{Introdução: a qualidade do número e as suas circunstâncias}

A noção de número no De re aedificatoria ${ }^{403}$ comparece na definição tripartida de Alberti sobre o conceito central da arte edificatória - a concinidade - , constituída por numerus, finitio e collocatio para que a beleza seja “... a conformidade e a aliança de todas as partes no conjunto a que pertencem, em função do número determinado, da delimitação e da disposição observada" ${ }^{404}$, de forma tal que aquele "princípio absoluto e primeiro da natureza" esteja sempre presente na obra de arquitetura.

Apesar de esta comunicação não se centrar no estudo das proporções das obras edificadas de Alberti estudadas, entre outros autores, por Wittkower ${ }^{405}$ e March ${ }^{406}$, a noção de número participa na definição das relações dimensionais presentes naquelas obras, como também para assinalar eventos e datas.

Com efeito, se reparamos, a título exemplificativo, na faixa epigrafada do frontão da Igreja de Santa Maria Novella, em Florença, podemos constatar os seguintes dizeres: IOHANES - ORICELLARIVS • PAV • F • ANSAL - MCCCCLXX, isto é, "Giovani Rucellai, filho de Paolo, no ano da salvação, 1470" (Fig. 1).

403 LEON BATTISTA ALBERTI, L'Architettura. De re aedificatoria, texto latino e trad. ital. de Giovanni Orlandi. Intr. e notas de Paolo Portoghesi [...], 1966. Milão: Edizioni Il Polifilo, 2 vols; idem, De re aedificatoria, fac-símile da editio princeps, ed. de H.-K. Lücke, tomo IV do Alberti Index, Leon Battista Alberti, De re aedificatoria, 1975, Florença, 1485.

404 LEON BATTISTA ALBERTI, Da Arte Edificatória, Tradução, notas e revisão disciplinar de Mário Krüger, tradução de A. M. do Espírito Santo, Lisboa, Fundação Calouste Gulbenkian, 2011, Livro IX, cap. 5.

405 RUDOLF WITTKOWER, Architectural Principles in the Age of Humanism. Londres: Academy Editions, 1949.

406 LIONEL MARCH, "Renaissance mathematics and architectural proportion in Alberti's De re aedificatoria": Architectural Research Quartely, 1996, vol. 2, pp. 54-65; Idem, Architectonics of Humanism. Essays on Number in Architecture. Londres: Academy Editions, 1998; Idem, "Proportional design in L. B. Alberti's Tempio Malatestiano, Rimini": Architectural Research Quarterly, vol. 3, 1999, pp. 259-270. 


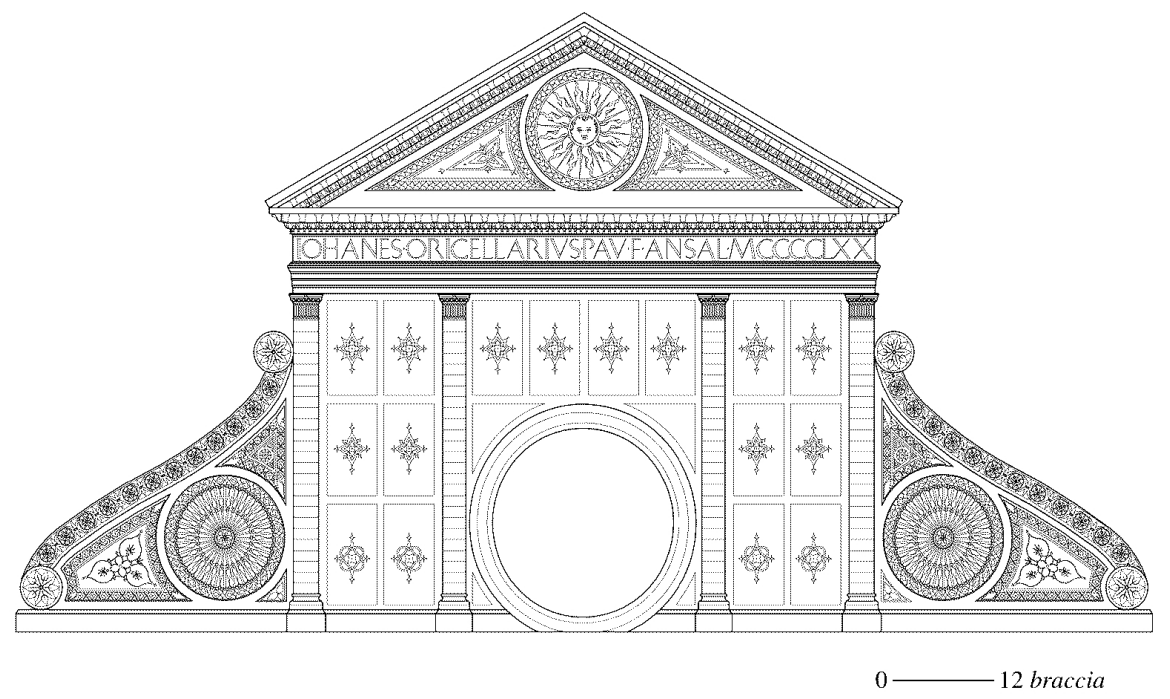

Fig. 1 Delineamento do frontão da fachada da Igreja de Santa Maria Novella, Florença ${ }^{407}$.

Se bem que a data escrita naquela faixa esteja redigida em numerais romanos, isto é, em letras romanas, para assinalar a conclusão da fachada de Santa Maria Novella, Alberti, de forma a acautelar a transmissão de dados numéricos nas cópias manuscritas do seu tratado, pede aos copistas "que refiram os números que forem utilizados, não pelos seus símbolos, mas pelas suas palavras completas, para que não sejam deturpados pelos erros" ${ }^{408}$.

407 Reprodução parcial do desenho executado pelo Arq. Bruno Figueiredo, cedido em agosto de 2013. O braccio mantuano é equivalente a $467 \mathrm{~mm}$.

408 LEON BATTISTA ALBERTI, op. cit., Livro VII, cap. 9. 


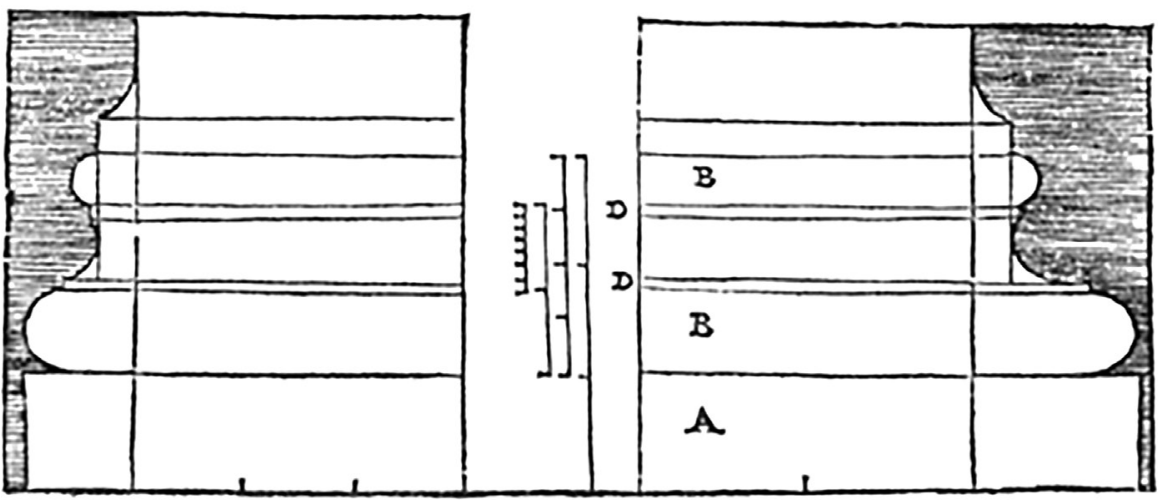

Fig. 2 Base do sistema de coluna Dórico de acordo com a interpretação de Bartoli, $1550^{409}$.

Esta advertência é integralmente cumprida, ao longo do De re aedificatoria, sempre que Alberti se refere a descrições numéricas de projetos e obras de arquitetura, como sucede na apresentação da base do sistema de coluna Dórico: "Dividiram a altura da base em três partes, das quais atribuíram uma parte à altura do plinto. A altura total da base era, pois, o triplo da altura do plinto, e a largura do plinto era também o triplo da altura da base. Excluído o plinto, dividiram o que restava da altura na base em quatro partes, das quais destinaram a de cima ao toro superior. A altura que fica no meio, entre o toro por cima e o plinto por baixo, dividiram-na ainda em duas partes, das quais atribuíram a inferior ao toro inferior e vazaram a superior para a escócia que está comprimida entre ambos os toros. A escócia consta de um canal vazado e de dois filetes que rodeiam os bordos do canal. Ao filete deram a sétima parte e vazaram o resto" 410 (Fig. 2).

Aquela advertência de Alberti sugere, contudo, que o controlo de obra era muito mais eficaz que o da reprodução de manuscritos, onde concorriam diversos estilos oscilantes de caligrafia, enquanto nas incisões epigrafadas nas suas obras construídas somente era utilizada a

409 LEON BATTISTA ALBERTI, L'Architettura di Leon Batista Alberti, tradotta in lingua fiorentina da Cosimo Bartoli [...] con la aggiunta de disegni, 1550, Florença: Lorenzo Torrentino.

410 LEON BATTISTA ALBERTI, op. cit., Livro VII, cap. 7. 
letra imperial romana restaurada, o que levanta algumas questões sobre a inteligibilidade da sua utilização manuscrita.

Para entendermos esta questão podemos cogitar em comparar numerais escritos numa notação posicional com uma sígnica. A notação posicional, como é o caso da numeração árabe, distingue-se de outras notações dado que utiliza o mesmo símbolo para diferentes ordens de magnitude, enquanto numa notação sígnica, como é a numeração romana, os números são representados por sinais numéricos em função da ordem de grandeza que representam.

Com efeito, os numerais romanos face aos algarismos árabes têm sido objeto, na contemporaneidade, de análises no domínio cognitivo, nomeadamente no que se refere ao aumento da velocidade e da precisão de leitura dos algarismos, quando comparados com os da numeração romana ${ }^{411}$. Também, mais recentemente, o estudo promovido por Wu et alii 412 mostrou que regiões cerebrais com diferentes padrões de ativação para operações aritméticas, elaboradas com numerais romanos e árabes, evidenciaram heterogeneidade funcional cerebral durante o processo de cognição, bem como confirmaram diferentes velocidades de resposta e níveis de precisão, tanto em termos de identificação como de cálculo.

No entanto, apesar de a numeração árabe ter sido introduzida no ocidente a partir do séc. XI, somente com a influência estabilizadora da imprensa é que os algarismos começaram a ser aceites de forma generalizada a partir do séc. XVI ${ }^{413}$, o que sugere a diminuta pertinência destes estudos cognitivos para se entender as questões relacionadas com a inteligibilidade da utilização dos numerais romanos no tempo de Alberti.

Reparemos, em vez disso, para as sucessivas redundâncias e sobreposições que se verificam entre o número de letras necessárias para a descrição de numerais romanos de I a X.

411 Cf. DALLIS K. PERRY, "Speed and Accuracy of Reading Arabic and Roman Numerals", in Journal of Applied Psychology, Vol. 36, 5, Oct. 1952, p. 346.

412 SARAH S. WU et alli, "Functional Heterogeneity of Inferior Parietal Cortex during Mathematical Cognition ... ”: Cereb Cortex. December, 2009, 19 (12), pp. 2930-45.

413 Cf. GEORGES IFRAH, Histoire Universelle des Chiffres. L'Intelligence des Hommes Racontée par les Nombres et le Calcul, Paris, Robert Laffont, 1994, p. 360. 


\begin{tabular}{cc} 
Número de Letras & Numerais Romanos \\
\hline 1 & I \\
2 & II \\
3 & III \\
2 & IV \\
1 & V \\
2 & VI \\
3 & VII \\
4 & VIII \\
2 & IX \\
1 & X \\
\hline
\end{tabular}

Tabela 1 Numerais romanos de I a X e número de letras necessários para a sua descrição.

Com efeito, na Tabela 1 podemos constatar que os numerais I, $\mathrm{V}$ e $\mathrm{X}$ necessitam de uma letra romana para serem descritos, os numerais II, IV, VI e IX precisam de duas, os numerais III e VII de três e, finalmente, o numeral VIII de quatro. Esta simples constatação mostra uma distribuição não uniforme de letras pelos numerais o que induziria, mais facilmente, a ocorrência de erros na sua transposição de manuscrito para manuscrito.

Além disso, também podemos verificar que o número de letras necessárias para a descrição dos numerais de I a CI segue um padrão repetitivo que gera sucessivas e alternadas redundâncias capazes de aumentar a ocorrência de erros na sua transcrição (Fig. 3). 
Número de Letras

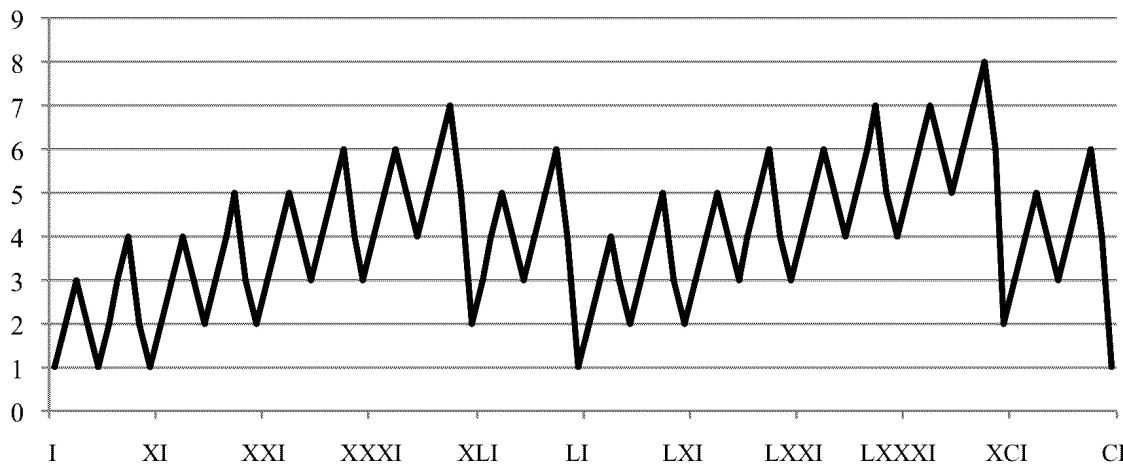

Numerais Romanos

Fig. 3 Numerais romanos de I a CI e número de letras necessárias para a sua descrição.

Em síntese, o número de letras necessárias para expressar os numerais romanos cresce de forma regular e cíclica à medida que se aumenta a sua cardinalidade, o que é um dos principais impedimentos para a sua correta representação e manipulação.

Apesar daquelas precauções os erros de transcrição ainda persistem no De re aedificatoria como pode ser constatado na descrição que Alberti faz das dimensões dos templos de planta central:

"Nos templos circulares, alguns tomaram três quartos do seu diâmetro, a grande maioria dois terços, ninguém menos de metade e com essas medidas erguiam o muro interior até à abóbada. Mas os mais peritos dividiram o perímetro dessa área circular em quatro partes e endireitaram uma dessas linhas e ergueram o muro interior com esse comprimento, que correspondia a uma proporção de onze para quatro (undecim ad quattuor)" 414 . 


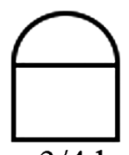

$3 / 4 d$

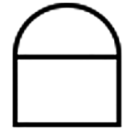

$2 / 3 d$

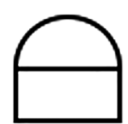

$1 / 2 \mathrm{~d}$

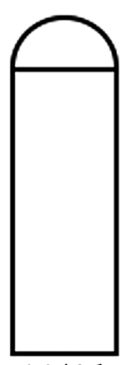

$11 / 4 d$

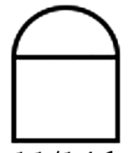

$11 / 14 d$

Fig. 4 Alturas de templos circulares em função do respetivo diâmetro.

Neste caso, possivelmente ocorreu um lapso, que Alberti queria a todo custo evitar, na transcrição da proporção 11/4 (undecim ad quattuor) a partir do manuscrito original, visto que a relação $\pi d / 4$ (onde $d$ representa o diâmetro da área circular) é equivalente a cerca de 11/14 d (undecim ad quattuordecim).

Assim, nos templos circulares, a altura do muro interior até à abóbada, que correspondia à retificação de um quarto de circunferência, era equivalente a 11/14 d e não a 11/4 d (Fig. 4) 415 .

Com efeito, nas anotações aos Elementa Geometriae de Euclides (circa 325-270 a.C.), traduzida por Campano da Novara (1255), existente na Biblioteca Nazionale Marciana, cod. Lat. VII 39 (3271- f. 135v), Alberti apresenta o seguinte comentário à obra de Arquimedes De mensura circuli: "Proportio aree omnis circuli ad quadratum diametri sue est sicut XI ad XIIII" (O ratio entre a área do círculo para o quadrado do seu diâmetro é $11 / 14)^{416}$, o que reforça a hipótese de um erro de transcrição no De re aedificatoria.

415 Comunicação do Prof. Lionel March, junho 2010; Cf. KIM WILLIAMS, LIONEL MARCH - STEPHEN R. WASSEL, The Mathematical Works of Leon Battista Alberti, 2010, Basel: Springer, pp. 211-212.

416 Cf. PAOLA MASSALIN - BRANKO MITROVIĆ, "Alberti and Euclid", in Albertiana, Vol. XI-XII, 2008-9, pp. 172 e 192. 
Como se isso não bastasse, a notação da numeração romana, ainda no séc. XVI, não estava totalmente estabilizada, como sucede na obra Mysticae numerorum significationis ..., uma tentativa para harmonizar a doutrina pitagórica com a cristã, de Petro Bongo ${ }^{417}$ e publicada em CIJIJXXCV, isto é, em MDLXXXV (1585), onde CIJ equivale a M, IO a D, XXC a LXXX e somente $\mathrm{V}$ se mantêm inalterado em relação à notação utilizada nos tempos de Alberti.

Estas considerações confirmam e justificam a insistência de Alberti em sugerir, no De re aedificatoria, a descrição dos numerais romanos de forma textual, de forma a evitar erros de transcrição de manuscrito para manuscrito.

\section{As dimensões pitagóricas dos sistemas de números albertianos}

As reflexões de Alberti sobre os sistemas de numeração utilizados, para além de serem descritos pela notação romana, apresentam uma base nitidamente pitagórica, a que não é estranha uma inerente dimensão qualitativa.

De acordo com esta tradição Alberti omite a descrição dos números um e dois, dado que são a nascente de todos os outros, e começa por descrever os remanescentes como pares ou ímpares intimamente relacionados, por lado, com arte edificatória: "Seguindo a natureza, nunca dispuseram em parte alguma em número ímpar os ossos do edifício, isto é as colunas, os ângulos e outros elementos do mesmo género. Pelo contrário, em nenhuma parte puseram aberturas em número par" e, por outro, com o corpo humano e o firmamento: "Efetivamente, todos os filósofos afirmam que a natureza consta de um princípio ternário. E quanto ao quinário, como é o caso das mãos dos homens, com razão o considero divino. E com o septenário sabemos que se delicia extraordinariamente o supremo artífice do universo. Ainda entre os números ímpares celebram o número nove em cujo número estão as esferas que a engenhosa natureza

417 PETRO R. D. BONGO, Mysticae numerorum significationis liber in duas divisus partes. Bergomi: typis Comini Venturae, \& socij: sumptibus... Francisci Franc. Senensis. 1685. 
implantou no firmamento" ${ }^{418}$. Ainda justifica os restantes números pares em considerações de ordem filosófica e refere-se aos números perfeitos nestes termos: "De entre os números pares houve filósofos que, consagrando o número quaternário, o dedicaram à divindade e por meio dele quiseram prestar-lhe os juramentos mais solenes. E, entre pouquíssimos, designaram como perfeito o senário porque é a soma de todos os seus divisores inteiros. Está à vista que o octonário desempenha um papel importante na natureza. Excepto no Egipto, vemos que não sobreviviam as crianças que nasciam de oito meses. Aristóteles considerava que o número dez era tido pelo mais perfeito de todos, talvez, como se pensa, porque o seu quadrado é formado pela soma dos seus primeiros quatro cubos consecutivos" 419 .

Estas referências, baseadas na numeração romana, são transversais no tratado de Alberti e compreendem todos os géneros de números expressos em língua latina, designadamente os cardinais (quantos): unus, duo, tres, quattor, quinque, sex, septem, ...; os ordinais (ordem numérica): primus, secundos, tertius, quartus, quintus, ...; os distributivos (partição): singuli, bini, terni, quaterni, quini, seni, septeni, ...; os advérbios numerais (quantidade de vezes): semel, bis, ter, quater, quinquies ...; os multiplicativos (número de classes): simplex, duplex, triplex, quadruplex, ... e, ainda, os proporcionais (uma ou mais vezes): simplus, duplus, triplus, quadrupulus, ... ${ }^{420 .}$

Como vimos, na sintética descrição que Alberti faz da base do sistema de coluna Dórico (Fig. 2), são utilizados diversas vezes os cardinais uma, duas, três e quatro, bem como o ordinal sétima e o proporcional triplo, o que mostra uma constante exposição dos numerais pelas suas palavras.

A cultura aritmética de Alberti ${ }^{421}$ é, de igual modo, extensa apesar de expressamente declarar que não pretende ser um "Nicómaco com os números" 422. Com efeito, começa por citar este autor que, na sua

418 LEON BATTISTA ALBERTI, op. cit., Livro IX, cap. 5.

419 LEON BATTISTA ALBERTI, Ibidem,

420 Cf. HANS-KARL LÜCKE, Index verborum, Munique, Prestel, 1975, p. 892.

421 LEON BATTISTA ALBERTI, op. cit., Livro IX, cap. 10.

422 LEON BATTISTA ALBERTI, op. cit., Livro III, cap. 2. Este autor chega a fazer diversas referências a uma obra de sua lavra sobre aritmética e geometria (Comentarii rerum mathematicarum) que não foi encontrada, até hoje, no seu espólio. 
Introdução à Aritmética (c. 60-120 d.C.), apresenta tabelas de sucessões de inteiros nas proporções de 1-2-3 e 1-3-4, bem como números poligonais para gerar tanto as consonâncias musicais, como as formas de templos de planta central e basilical, tendo por fundamento a máxima de Pitágoras: "'É certíssimo que a natureza é absolutamente igual a si mesma em todas as coisas. ${ }^{423}$ Assim é de fato. Os números, pelos quais se faz com que a concinidade das vozes se torne agradabilíssima aos ouvidos, são os mesmos que fazem com que os olhos e o espírito se encham de um prazer maravilhoso" 424 .

Esta problemática, no que se refere à controvérsia inatismo-construtivismo, não é exclusiva das áreas das artes e da arquitetura, mas está também presente na investigação sobre os processos cognitivos na aprendizagem da aritmética (um dos alicerces dos sistemas proporcionais em Alberti), como sugere Ferreira, ao analisar as estratégias de problemas de estrutura aditiva em crianças de 5/6 anos de idade, onde assinala que estas "[...] muito antes de compreenderem a noção de conservação das quantidades numéricas, são capazes de resolver problemas que incluem transformações numéricas, de pequenas quantidades. No entanto, levanta-se a questão se essas capacidades são de natureza inata, ou se o processo de desenvolvimento do conhecimento numérico se baseia numa construção demorada e complexa, essencialmente de natureza ontogenética”. 425

Todavia, para os pitagóricos não só todo o número tem uma representação espacial, como toda a figura apresenta um número inato, daí a importância atribuída à década e à tectractys, que mostra que o número 10 , representado por uma forma triangular com pontos equidistantes, é a soma dos números $1,2,3,4: \therefore$.

423 Cf. PSEUDO-PITÁGORAS, in Aurea verba, I versi aurei di Pitagora, Trad. It., intr. e notas de A. Farina, Nápoles, Libreria scientifica, 1962, p. 52.

${ }^{424}$ LEON BATTISTA ALBERTI, op. cit., Livro IX, cap. 5.

425 MARIA DA CONCEIÇÃO RODRIGUES FERREIRA, Análises das Estratégias de Resolução de Problemas de Estrutura Aditiva em Crianças de 5-6 anos de Idade. Tese de Doutoramento apresentada na Faculdade de Psicologia e de Ciências da Educação da Universidade de Coimbra, Coimbra, 2003, p. 86. 


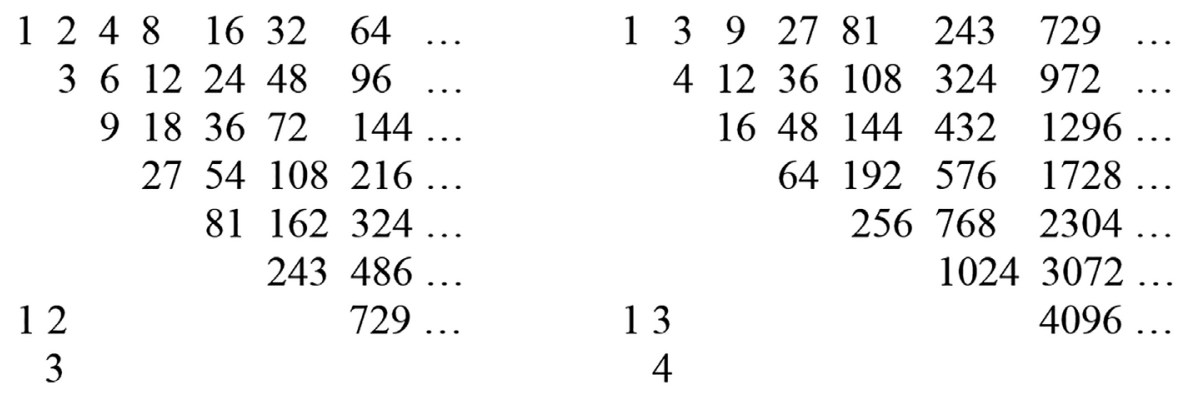

Tabela 2 - Tabelas de sucessões de números inteiros nas proporções de 1-2-3 e 1-3-4, apresentadas por Nicómaco de Gerasa (II, 12) na "Introdução à Aritmética" (Arithmetike eisagoge).

Este princípio da harmonia universal pode ser descrito pelas sucessões de números inteiros, nas proporções de 1-2-3 e 1-3-4, de Nicómaco de Gerasa (Tabela 2) que, por seu lado, se reveem na noção de número harmónico de Philippe de Vitry, conforme exposto na Ars nova ${ }^{426}$.

Um número harmónico $(\mathrm{H})$ é qualquer inteiro não divisível por nenhum número primo, como mostrado por Lenstra ${ }^{427}$, excepto pelos números 2 ou 3 , isto é, $\mathrm{H}=2^{\mathrm{m}} 3^{\mathrm{n}}$, onde $\mathrm{m}$ e $\mathrm{n}$ são números inteiros (Tabela 3 ).

426 PHILIPPE DE VITRY, "Ars nova”, c.1322-23. In Philippe de Vitry's 'Ars Nova': A Translation. Trad. ingl. de L. Plantinga. Journal of Music Theory, Vol. 5, No. 2, 1961, pp. 204-223. Vitry estabelece uma teoria da notação musical, introduz inovadores sistemas rítmicos e formula a noção de número harmónico que pode ser escrito como uma potência de 2 multiplicado por uma potência de 3 .

427 HENDRIK LENSTRA, “Aeternitatem cogita”: Nieuw Archief voor Wiskunde, 2001, 5/2, n. ${ }^{\circ}$ 2, pp. 23-26. 


$\begin{array}{llllllll}\mathrm{m} / \mathrm{n} & 0 & 1 & 2 & 3 & 4 & 5 & 6 \\ 0 & 1 & 3 & 9 & 27 & 81 & 243 & 729 \\ 1 & 2 & 6 & 18 & 54 & 162 & 486 & \\ 2 & 4 & 12 & 36 & 108 & 324 & 972 & \\ 3 & 8 & 24 & 72 & 216 & 648 & & \\ 4 & 16 & 48 & 144 & 432 & & & \\ 5 & 32 & 96 & 288 & 864 & & & \\ 6 & 64 & 192 & 576 & & & & \\ 7 & 128 & 384 & & & & & \\ 8 & 256 & 768 & & & & & \\ 9 & 512 & & & & & & \end{array}$

Tabela 3 Números harmónicos derivados a partir da relação $\mathrm{H}=2^{\mathrm{m}} 3^{\mathrm{n}}$, onde $\mathrm{n}=0, \ldots, 6$ e $\mathrm{m}=0, \ldots, 9$.

Esta Tabela apresenta os números harmónicos de Philipe de Vitry, também patentes nas tabelas de sucessões de números inteiros descritas anteriormente por Nicómaco de Gerasa ${ }^{428}$ (Tabela 2). Este, por seu lado, ainda introduz a noção de número poligonal, como sendo uma combinação geométrica regular de pontos igualmente espaçados de modo a formarem um polígono regular (Tabela 4).

$\begin{array}{lllllllllll}\text { Triangulares } & 1 & \mathbf{3} & \mathbf{6} & \mathbf{1 0} & \mathbf{1 5} & \mathbf{2 1} & 28 & 36 & 45 & 55 \\ \text { Quadrados } & 1 & \mathbf{4} & \mathbf{9} & \mathbf{1 6} & \mathbf{2 5} & \mathbf{3 6} & 49 & 64 & 81 & 100 \\ \text { Pentagonais } & 1 & \mathbf{5} & \mathbf{1 2} & \mathbf{2 2} & \mathbf{3 5} & \mathbf{5 1} & 70 & 92 & 117 & 145 \\ \text { Hexagonais } & 1 & \mathbf{6} & \mathbf{1 5} & \mathbf{2 8} & \mathbf{4 5} & \mathbf{6 6} & 91 & 120 & 153 & 190 \\ \text { Heptagonais } & 1 & \mathbf{7} & \mathbf{1 8} & \mathbf{3 4} & \mathbf{5 5} & \mathbf{8 1} & 112 & 148 & 189 & 235\end{array}$

Tabela 4 Números poligonais de acordo com Nicómaco de Gerasa (II, 12) ${ }^{429}$. Os números a negrito estão representados por figuras geométricas na Fig. 4.

Estes números poligonais, que representam a quantidade de pontos equidistantes que as figuras triangulares, quadradas, pentagonais,

428 NICÓMACO DE GERASA, Introduction to Arithmetic. Trad. ingl. de M. L. D'Ooge. Winnipeg: St. John's College Press, 1960.

429 Cf. NICÓMACO DE GERASA, op. cit., p. 248. 
hexagonais e heptagonais podem apresentar, são um traço de união entre uma descrição aritmética e uma geométrica de uma harmonia cósmica universal.

A adesão a este sistema de números é afirmada por Alberti ${ }^{430}$ : "Por isso, antes de mais estaremos atentos a que todas as coisas, mesmo as mais pequenas, sejam dispostas com o nível e o cordel e de acordo com os números, a forma e a figura, de tal modo que as da direita correspondam inteiramente às da esquerda, as de cima às de baixo, as próximas às próximas, as iguais às iguais, para ornamento do corpo de que hão-de ser partes".

De acordo com Sbacchi ${ }^{431}$, Alberti somente se refere a questões geométricas na obra Ludi rerum mathematicarum o que sugere, dada a ausência de referências explícitas a métodos euclidianos no De re aedificatoria, a primazia das rationes numéricas sobre figuras geométricas, o que não pode ser aceite de acordo com o levantamento, elaborado mais recentemente por Massalin - Mitrović ${ }^{432}$, das anotações feitas por Alberti no tratado de Euclides, traduzido por Campano da Novara em 1255, e que mostram um completo entendimento das relações entre aritmética e geometria.

430 LEON BATTISTA ALBERTI, op. cit., Livro IX, cap. 5.A

431 MICHELE SBACCHI (2001) "Euclidism and Theory of Architecture": NEXUS Network Journal, 2001, V. 3, n. ${ }^{\circ}$ 2, pp. 25-28.

432 PAOLA MASSALIN - BRANKO MITROVIĆ, "Alberti and Euclid": Albertiana, 2008-9, Vol. XI-XII, p. 172 e 192. 


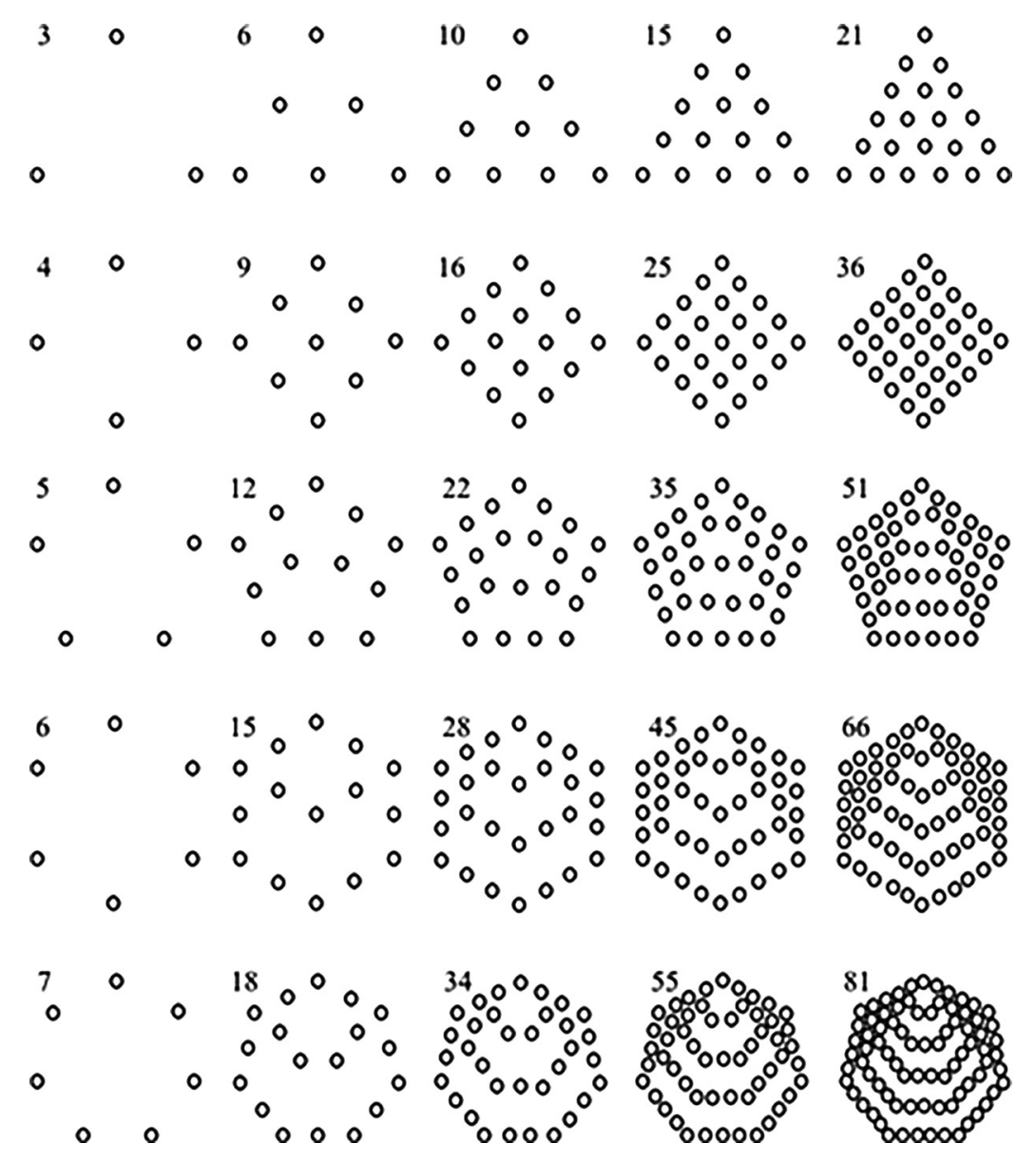

Fig. 5 Números poligonais, representados a negrito na Tabela 4, para figuras geométricas triangulares, quadradas, pentagonais, hexagonais e heptagonais.

Com efeito, Alberti ${ }^{433}$ propõe nove geometrias possíveis "de acordo com os números, a forma e a figura" para os templos com plantas central e basilical: o círculo ("a forma eleita pela natureza”), cinco polígonos (quadrado, hexágono, octágono, decágono e dodecágono) e três rectângulos (um duplo quadrado, um quadrado e meio e um quadrado e um terço $)^{434}$. (Fig. 6)

433 LEON BATTISTA ALBERTI, op. cit., Livro VII, cap. 4.

434 Note-se que os números octogonais, decagonais e dodecagonais também são números poligonais, apesar de Nicómaco de Gerasa não se referir explicitamente aos mesmos (Tabela 4). 
Este pensamento de origem pitagórica centra-se numa ideia matemática, metafísica e estética sobre o conceito de número. Os números combinam-se entre si formando uma harmonia de opostos (par-ímpar, limitado-ilimitado, etc.) que produz um acordo de ordem estética musical.

Esta ideia de uma harmonia universal, que permeia todos os campos do saber como das atividades humanas, é inteiramente assumida por Alberti ${ }^{435}$ : "Dizemos que a harmonia é uma consonância agradável aos ouvidos. Os sons dividem-se em graves e agudos. Um som grave ressoa a partir da corda mais comprida, e os agudos a partir das cordas mais curtas. As várias diferenças destes sons produzem as várias harmonias que os Antigos, tendo em conta a comparação entre as cordas consoantes, reuniram num conjunto de números fixos".
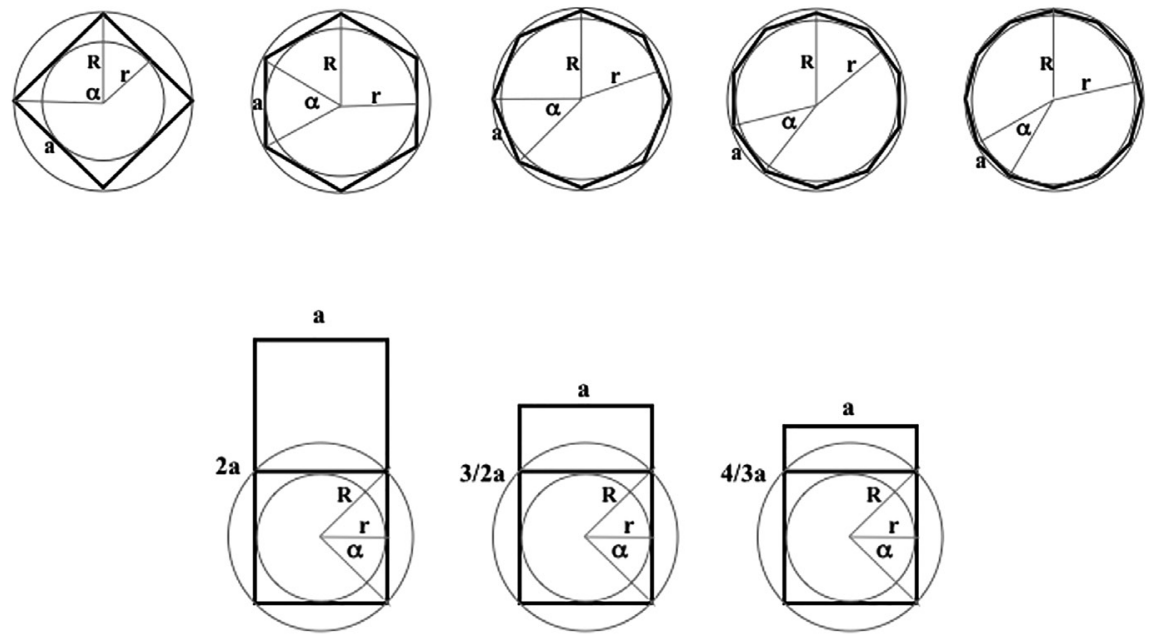

Fig. 6 As nove geometrias possíveis para os templos com plantas central e basilical sugeridas por Alberti (VII, 4), onde R é o raio invariante da circunferência circunscrita às formas poligonais, $\mathrm{r} o$ raio da circunferência inscrita, a um lado da forma poligonal e $\alpha$ o ângulo que subtende um lado desta forma ${ }^{436}$.

435 LEON BATTISTA ALBERTI, op. cit., Livro IX, cap. 5.

436 A descrição destas formas geométricas por meio de linhas e ângulos, elaborada por Alberti (op. cit., Livro VII, cap. 4), mostra a variabilidade de dimensões lineares e angulares, bem como algumas formas poligonais se podem derivar de outras com menor número de lados. 
Deste modo, as comparações são feitas entre o comprimento de uma corda e a altura de um som, o que permite estabelecer uma quantificação numérica entre duas ou mais notas musicais e, consequentemente, transformar uma proporção harmónica numa aritmética e vice-versa.

Assim, por exemplo, 1/2 equivale ao intervalo de uma oitava, onde o número 2 representa a nota mais baixa e o 1 a mais elevada. Com efeito, se acrescentarmos a uma corda todo o seu comprimento, ela soará a um intervalo de oitava abaixo (mais grave) em relação à corda original. De modo inverso, se dividirmos uma corda em duas partes iguais, cada uma delas soará uma oitava acima (mais agudo) em relação à corda original.

A partir desta argumentação Alberti ${ }^{437}$ sugere a transposição das relações musicais greco-medievais para definir relações proporcionais entre duas medidas, quer estas se refiram a áreas pequenas, médias ou grandes, a saber ${ }^{438}$ :

Áreas pequenas
Quadrado 1/1 : uníssuno,
Sesquiáltera $2 / 3$ : quinta perfeita,
Sesquitércia $3 / 4$ : quarta perfeita.

Áreas médias

Dupla $1 / 2$ : oitava,

A Sesquiáltera duplicada $(2 / 3)(2 / 3)=4 / 9$ : duas quintas,

A Sesquitércia duplicada $(3 / 4)(3 / 4)=9 / 16$ : duas quartas.

\section{Áreas grandes}

A Tripla $(1 / 2)(2 / 3)=1 / 3$ : uma oitava mais uma quinta perfeita,

A Dupla Sesquitércia $(1 / 2)(3 / 4)=3 / 8$ : uma oitava mais uma quarta perfeita.

A Quádrupla $(1 / 2)(1 / 2)=1 / 4$ : duas oitavas ${ }^{439}$.

437 LEON BATTISTA ALBERTI, Ibidem,

438 Apesar de Alberti não definir o que entende por áreas pequenas, médias e grandes, que se reportam à sua geometria retangular e não à sua dimensão, existe um sentido de proporcionalidade das áreas grandes, com menores valores numéricos (as duas oitavas), para as áreas pequenas com maiores valores (o uníssuno). Ver Tabela 4.

$439 \mathrm{Na}$ terminologia utilizada por Alberti sesqui refere-se à palavra latina que significa um e meio, pente à palavra grega que significa cinco e dia corresponde ao elemento de formação de palavras gregas e que traduz a ideia de passagem, de intervalo ou de separação. 
Neste sistema proporcional as rationes compostas por outras harmónicas mais simples, revelam partições numéricas cujas dimensões são consonantes com os intervalos da escala musical. Assim, tanto a aritmética como a edificatória, à semelhança da música, era vista como um símbolo visível de uma ordem universal, como se fosse uma manifestação da harmonia do cosmos.

Neste sentido, um elemento construtivo, seja uma parede, um piso ou uma abertura, que apresente as proporções de $1 / 2$, a que equivale musicalmente uma oitava, é composta de duas rationes, dado que $1 / 2=(2 / 3)$ (3/4), a que corresponde uma experiência espacial em uníssono com a ordem matemática do cosmos. Do mesmo modo que harmonias musicais governavam o movimento dos planetas, que produziam a música das esferas, não percetível, também se estabelecia na edificatória um sistema de proporções não visível, cuja validade cósmica não era posta em causa, como Alberti 440 faz questão de sublinhar, como vimos, ao referir-se às "esferas que a engenhosa natureza implantou no firmamento".
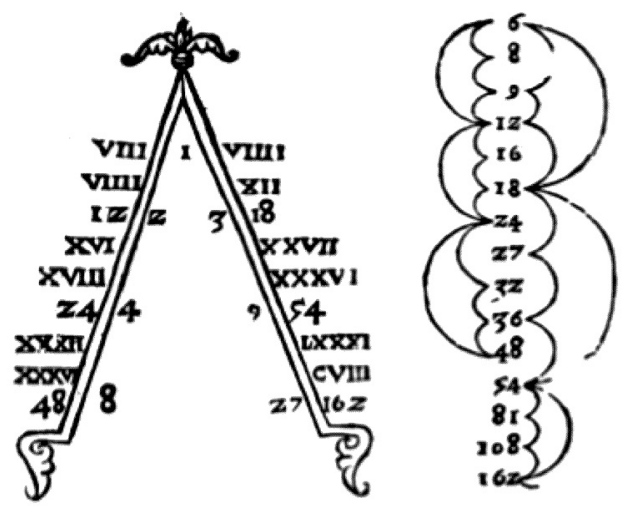

Fig. 7 O lambda $(\Lambda)$ pitagórico com progressões de 2 e 3 formulado por Francesco Giorgi na obra De harmonia mundi totius cantica tria, 1525.

No entanto, apenas os números harmónicos 1, 2, 3, 4, 8, 9 e 16 de Philipe de Vitry (Tabela 4) é que participam na formação destas

440 LEON BATTISTA ALBERTI, op. cit, Livro IX, cap. 5. 
consonâncias musicais oriundas das teorias pitagóricas adotadas por Alberti, o que indica que estas são demasiado restritivas em relação ao universo de números harmónicos.

Francesco Giorgi ${ }^{441}$ na obra De harmonia mundi totius cantica tria, publicada em 1525, representa o lambda $(\Lambda)$ pitagórico com progressões de 2 e 3, onde os números são multiplicados por 6 para eliminar as frações e os intervalos e sub-intervalos musicais são ilustrados por arcos (Fig. 7). Neste caso, os números 9, 27, 81, 6, 18, 54, 162, 12, 36, 108, 8, 24, 16, 48, 32 já constam da Tabela de Philipe de Vitry.

\section{Números perfeitos e correspondentiae inatae}

Talvez por as consonâncias musicais de Alberti serem limitadas na utilização de números harmónicos é que são introduzidas mais duas categorias de números: os números perfeitos e as correspondentiae inatae, de forma a obter um universo mais alargado de rationes.

Com efeito, Alberti indica, em relação a estas relações, que "na definição das medidas há proporções inatas que não se podem determinar de forma alguma por meio dos números, mas se conseguem representar mediante raízes e potências" 442 .

Um número inteiro diz-se perfeito quando é idêntico à soma de todos os seus divisores. Assim, $6=1+2+3,28=1+2+4+14$ e $496=$ $1+2+4+8+16+31+62+124+248$ são os três primeiros números perfeitos.

Euclides postulou que, "se vários números, começando pela unidade, se dispuserem em proporção duplicada [em potências de dois] e o conjunto de todos eles [a sua soma] for um número primo, o produto deste conjunto pelo último será um número perfeito" ${ }^{443}$. Por outras palavras, se $1+2+2^{2}+\ldots+2^{\mathrm{n}-1}$ for um número primo, então o produto

441 FRANCESCO GIORGI, "De harmonia mundi totius cantica tria". Veneza: in aedibus Bernardini de vitalibus chalcographi, 1525.

442 LEON BATTISTA ALBERTI, op. cit., Livro IX, cap. 6.

443 EUCLIDES, Elementa Geometriae. Veneza. The Bancroft Library; University of California, Berkeley, 1482. 
$\left(1+2+2^{2}+\ldots+2^{\mathrm{n}-1}\right) \cdot 2^{\mathrm{n}-1}$ é um número perfeito. Os números 6,28 e 496 satisfazem esta relação.

O número 10 era igualmente considerado por Aristóteles ${ }^{444}$ perfeito, apesar de este utilizar outro critério para o definir, na medida em que o seu quadrado deveria corresponder à soma dos cubos dos quatro primeiros inteiros $\left(10^{2}=1^{3}+2^{3}+3^{3}+4^{3}\right)$. Por dedução, mostra-se que o somatório de n números cúbicos $\left(1^{3}+2^{3}+3^{3}+\ldots+n^{3}\right)$ é igual a $[1 / 2 n(n+1)]^{2} 445$. Assim, os números $1,3,6,10,15,21,28, \ldots$, também podem, segundo esta definição, ser considerados números perfeitos.

Contudo, o número 10 não é idêntico à soma dos seus divisores, i.e. $10 \neq 1+2+5$ e, consequentemente, não é um número perfeito na aceção de Euclides. Entre os números menores ou iguais a 10, somente o 6 satisfaz, simultaneamente, os critérios de Aristóteles e de Euclides, para número perfeito.

Como vimos, Alberti ${ }^{446}$ aceita como número perfeito o senário, bem como o número dez, o que significa que utiliza diferentes critérios, seja baseado em Euclides ${ }^{447}$, ora em Aristóteles ${ }^{448}$, para definir estes números ${ }^{449}$.

Além dos sistemas proporcionais baseados em números inteiros, sejam oriundos das analogias musicais ou dos números perfeitos, Alberti 450 também se refere às proporções a partir das correspondentiae inatae, que podem ser definidas a partir de um cubo unitário, em que as faces apresentam uma diagonal idêntica a $\sqrt{ } 2$, o cubo uma diagonal igual a $\sqrt{ } 3$ e, para um rectângulo de lados iguais a $\sqrt{ } 3$ e 1 , uma diagonal idêntica a $\sqrt{4}=2$ (Fig. 8).

${ }^{444}$ ARISTÓTELES, Metafísica, Intr. de M. Candel e trad. Esp. de P. Azcárate. Espasa Calpe, S.A., Madrid, 2007, Livro I, Cap. 5.

445 Cf. JAN GULlBerG, Mathematics: From the Birth of Numbers, W. W. Norton \& Company, Nova Iorque, 1997, p. 294.

446 LEON BATTISTA ALBERTI, op. cit, Livro X, cap. 5.

${ }^{447}$ EUCLIDES, Ibidem,

448 ARISTÓTELES, Ibidem,

449 Se exceptuarmos o número 2 , tanto as representações numéricas das consonâncias musicais, como os números perfeitos referidos por Alberti, podem ser entendidos como números poligonais na aceção de Nicómaco de Gerasa.

450 LEON BATTISTA ALBERTI, op. cit., Livro IX, cap. 6. 

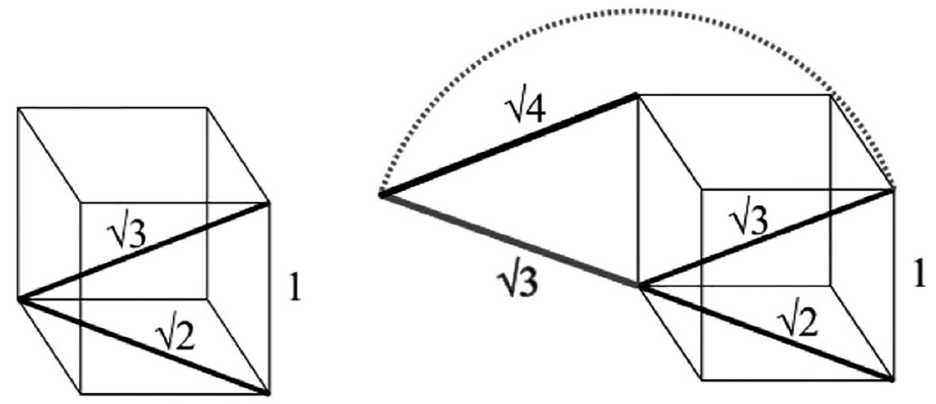

Fig. 8 Geração de $\sqrt{ } 2, \sqrt{ } 3$ e $\sqrt{ } 4$ a partir de um cubo unitário.

De acordo com a proposição II, 10 dos Elementa geometriae de Euclides duas grandezas são comensuráveis se existe uma terceira grandeza de tal modo que as duas primeiras são múltiplas da terceira. Caso contrário, são incomensuráveis. Assim, Euclides não afirma que a raiz quadrada de dois é um número irracional, mas prova que a diagonal de um quadrado é incomensurável com o seu lado. Além disso, nas proposições XIII, 14 e 15, este raciocínio é transposto para a descrição das diagonais de um cubo.

Consequentemente e dado que para Alberti “... a própria unidade não é um número mas a nascente [de acordo com a emanação de origem neo-platónica] dos números que se contém a si mesma e se derrama, talvez seja legítimo dizer que o primeiro número é a dualidade"451, isto significa que também vai utilizar um cubo, para definir as correspondências inatas, mas com duas unidades de aresta, o que origina uma medida de $\sqrt{ } 8$ nas diagonais das faces e outra de $\sqrt{ } 12$ nas diagonais do cubo. Por outras palavras, em relação a um cubo unitário os valores de $\sqrt{2}$ e $\sqrt{3}$ foram duplicados, não se alterando, no entanto, a sua interpretação como números irracionais ou incomensuráveis.

451 LEON BATTISTA ALBERTI, Ibidem. 


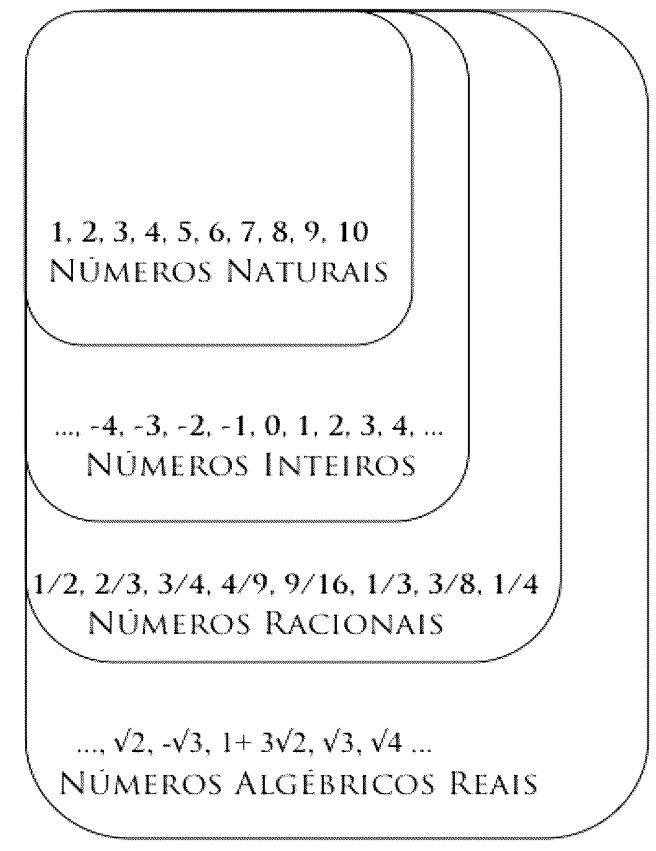

Fig. 9 O universo dos sistemas numéricos de Alberti, sistematizado a partir da atual noção de número.

Para um leitor contemporâneo os números perfeitos e os resultantes das consonâncias musicais podem ser vistos como um subconjunto dos números naturais $\{1,2,3, \ldots, 10\}$, bem como dos números inteiros $\{0,1,2,3, \ldots, 10\}$, se excetuarmos os números negativos e atendermos a que Alberti utiliza o zero na Descriptio Urbis Romae ${ }^{452}$, para descrever o plano desta cidade, por meio de coordenadas polares que indicam a direção e a distância (borizon e radius) a partir do Capitólio, que se apresenta com coordenadas nulas 453 . Também as proporções aritméticas resultantes das consonâncias musicais podem ser consideradas como números racionais expressos como uma fração

452 LEON BATTISTA ALBERTI, Descriptio urbis Romae, 1450. Ed. crítica, trad. fr. e comentário de M. Furno e M. Carpo, 2000. Paris: Droz.

453 O número zero foi introduzido no ocidente por Leonardo de Pisa, dito Fibonacci, e publicado em 1202: "As nove cifras indianas (figurae indorum), são as seguintes: 9, 8, 7, 6, $5,4,3,2,1$. Com estas nove cifras (novem figuris), juntamente com símbolo 0, que se chama zephirum em árabe, escrevem-se todos os números (numerus) que se quiser". Cf. FIBONACCI, Liber Abbaci. Trad. de E. L. Sigler, 2002, Fibonacci's Liber Abaci. Nova Iorque: Springer-Verlag. 
de um inteiro $\{1 / 2,2 / 3,3 / 4,4 / 9,9 / 16,1 / 3,3 / 8,1 / 4\}$ e, por último, as correspondências inatas como um subconjunto dos números algébricos reais ou irracionais, desde que excetuemos os valores negativos $\{\sqrt{ } 2, \sqrt{3}, \sqrt{4}\}$ (Fig. 9).

No entanto, esta generalização dos números naturais para os irracionais, dos números comensuráveis para incomensuráveis, de uma representação finita para uma infinita é contrária ao entendimento que os antigos tinham da noção de número. Com efeito, Nicómaco de Gerasa ${ }^{454}$ define o número como plêthos hôrismenon, isto é, como multiplicidade limitada onde não se pode "deduzir o infinito a partir do finito, mas de conter o infinito pelo finito" 455 , como sugere a analogia da flauta de Boécio ${ }^{456}$, onde os orifícios das suas extremidades são imutáveis e quando se abrem ou se fecham os restantes produzem-se novas e variadas sonoridades, enquanto os extremos permanecem constantes gerando-se, dentro daqueles limites, as respectivas proporções aritméticas ${ }^{457}$.

\section{Conversões Decimais}

Para que estes diferentes sistemas numéricos sejam comparáveis numa mesma linha de base iremos proceder a duas transformações aritméticas: as conversões decimais e as convergências racionais.

A primeira transformação não teria sido possível de fazê-la no tempo de Alberti dado que os números decimais somente foram introduzidos por Simon Stevin 458 em 1585 na obra De Thiende (A Arte dos Dez) e,

454 NICÓMACO DE GERASA, op. cit., II, p. 50 e 1.

455 PIERRE CAYE, A Questão da Proporção. Reflexões para um Humanismo do quadrivium, Belo Horizonte, Editora UFMG, 2013, p. 280.

456 BOÉCIO, Boethian number theory. A translation of the De Institutione Arithmetica. Trad., intr. e notas de M. Masi, 2006. Amesterdão: Editions Rodopi.

457 Note-se que a noção de número como multiplicidade limitada também comparece em Aristóteles (op. cit.., 1020a13): a "multiplicidade, quando limitada é um número"; bem como em Plotino: “... a multiplicidade é um afastamento da Unidade, o infinito é a ausência completa, uma inumerável multiplicidade, e é por isso que o não limitado é um mal ...", não se restringindo aquele conceito de número aos autores anteriormente citados, isto é, a Nicómaco de Gerasa (op. cit.) e a Boécio (op. cit.). Cf. PLOTINO, The Enneads. Trad. ingl. de S. MacKenna, 1991, Londres: Penguin Books, VI, p. 6 e 1.

458 SIMON STEVIN, De Thiende, Ed. de A. J. E. M. Smeur, 1965. De Graaf, Nieuwkoop. 
mesmo assim, com uma notação arcaica como sucede, por exemplo, na consonância musical sesquitércia duplicada, expressa pela relação 9/16 = 0,5625, que seria escrita como 0 (2) 5(1) 6(2) 2(3) 5, onde os números no interior dos círculos corresponderiam às sucessivas casas decimais. Apenas a partir de 1691, após o estabelecimento da notação simplificada de Moderna, é que os números decimais passaram a ter uma aceitação plena ${ }^{459}$.

Note-se, também, que a descrição das proporções para Alberti pode ser obtida por meio de operações exclusivamente geométricas,

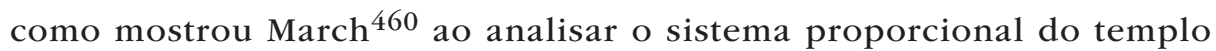
Malatestiano, em Rimini, não sendo, por isso, necessária a manipulação de frações numéricas, nem evidentemente a utilização do ponto decimal.

\begin{tabular}{|c|c|c|c|c|c|c|c|}
\hline & Numerador & Denominador & Ordenação & Seriação & Numerador & Denominador & \multirow{4}{*}{ Áreas Grandes } \\
\hline \multirow{4}{*}{ Áreas Pequenas } & 1 & 1 & 1 & 0,25 & 1 & 4 & \\
\hline & 2 & 3 & 0,666 & 0,333 & 1 & 3 & \\
\hline & 3 & 4 & 0,750 & 0,375 & 3 & 8 & \\
\hline & 1 & 2 & 0,500 & 0,444 & 4 & 9 & \multirow{4}{*}{ Áreas Médias } \\
\hline \multirow[t]{2}{*}{ Áreas Médias } & 4 & 9 & 0,444 & 0,500 & 1 & 2 & \\
\hline & 9 & 16 & 0,562 & 0,562 & 9 & 16 & \\
\hline \multirow{3}{*}{ Áreas Grandes } & 1 & 3 & 0,333 & 0,666 & 2 & 3 & \\
\hline & 3 & 8 & 0,375 & 0,750 & 3 & 4 & \multirow[t]{2}{*}{ Áreas Pequenas } \\
\hline & 1 & 4 & 0,250 & 1 & 1 & 1 & \\
\hline \multirow[t]{2}{*}{ Números Perfeitos } & 10 & 6 & 1,666 & 1,144 & 2 & $\sqrt{2}$ & \multirow{2}{*}{$\begin{array}{l}\text { Correspondentia } \\
\text { Inatae } \\
\text { Números Perfeitos }\end{array}$} \\
\hline & 2 & $\sqrt{2}$ & 1,144 & 1,666 & 10 & 6 & \\
\hline $\begin{array}{l}\text { Correspondentia } \\
\text { Inatae }\end{array}$ & $\begin{array}{l}3 \\
2\end{array}$ & $\begin{array}{c}\sqrt{3} \\
1\end{array}$ & $\begin{array}{c}1,732 \\
2\end{array}$ & $\begin{array}{c}1,732 \\
2 \\
\end{array}$ & $\begin{array}{l}3 \\
2\end{array}$ & $\begin{array}{l}\sqrt{3} \\
1\end{array}$ & $\begin{array}{c}\text { Correspondentic } \\
\text { Inatae }\end{array}$ \\
\hline
\end{tabular}

Tabela 5 Conversões decimais das consonâncias musicais, dos números perfeitos e das correspondentiae inatae, de acordo com a ordenação com que comparecem no De re aedificatoria, bem como na sua seriação, do menor para o maior valor.

459 Cf. TOBIAS DANTZIG, Número: A Linguagem da Ciência, Zahar Editores, Trad. port. de S. G. de Paula, Rio de Janeiro, 1970, p. 223.

460 LIONEL MARCH, Proportional design in L. B. Alberti's Tempio Malatestiano, Rimini, Quarterly Architectural Research, 1999, vol. 3, pp. 259-270. 
As conversões decimais das rationes propostas por Alberti permitem, no entanto, comparar numa mesma linha de base os diferentes sistemas numéricos, assentes em consonâncias musicais, correspondências inatas e números perfeitos, como aparecem mencionados no De re aedificatoria.

No lado esquerdo da Tabela 5 apresentam-se as conversões decimais das relações aritméticas das consonâncias musicais para as áreas pequenas, médias e grandes, bem como dos números perfeitos 6 e 10 e das correspondentiae inatae para $\sqrt{ } 2: 1, \sqrt{ } 3: 1$ e $\sqrt{ } 4: 1$, de acordo com a ordem de apresentação de como comparecem no Livro IX, cap. 5, do De re aedificatoria.

\section{Ordenação}

Valores Ordenados

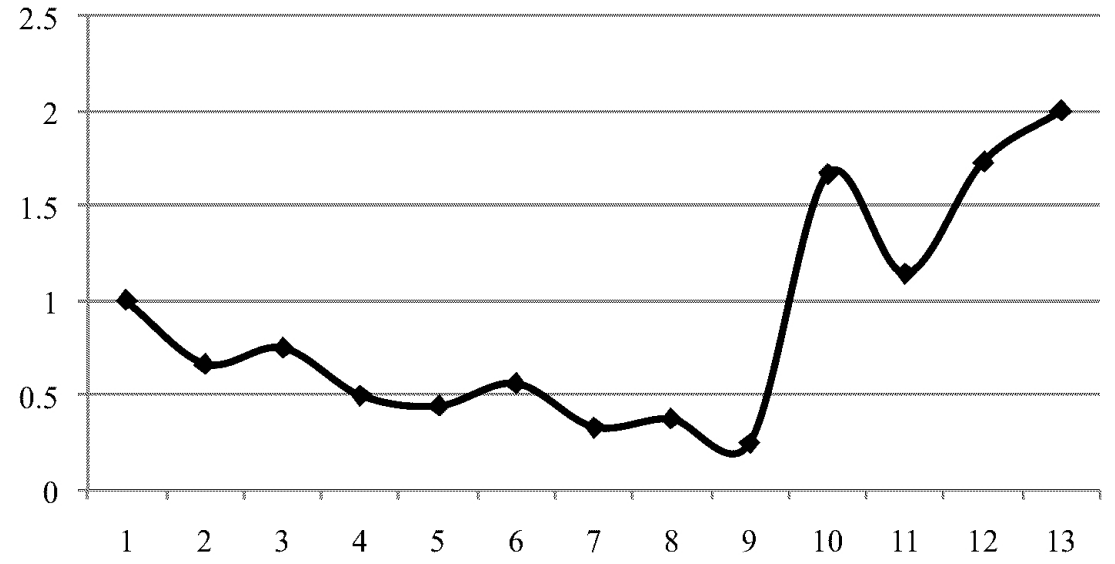

Ordenação

Fig. 10 Ordenação das consonâncias musicais, números perfeitos e correspondentiae inatae de acordo com a sequência de como comparecem no De re aedificatoria. 


\section{Seriação}

Valores Seriados

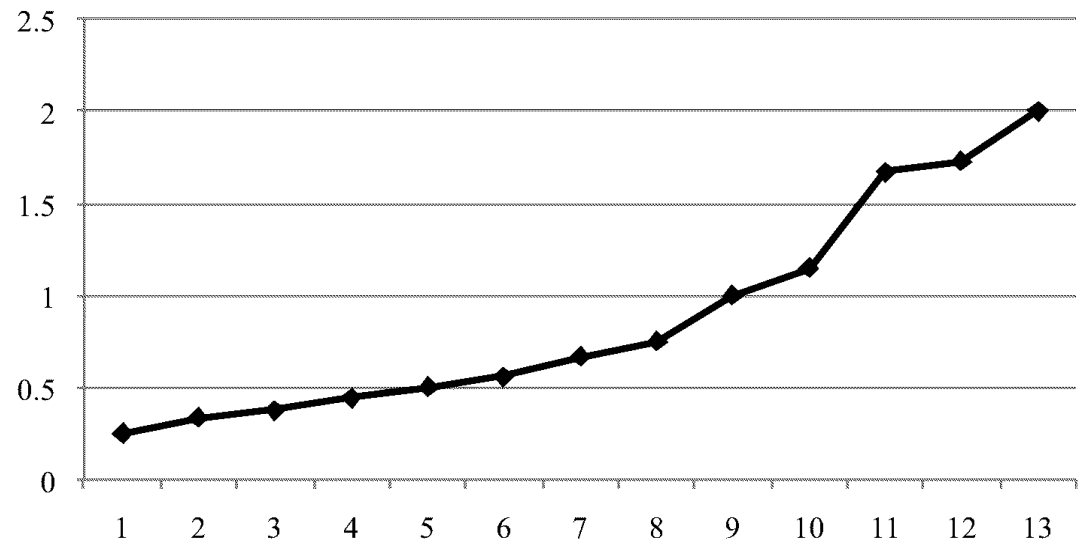

Seriação

Fig. 11 Seriação de forma crescente e monotónica, do menor para o maior valor, das consonâncias musicais, números perfeitos e correspondentiae inatae.

No lado direito desta Tabela comparecem as mesmas conversões decimais, mas agora seriadas de forma crescente, do menor para o maior valor.

Podemos notar que, ao contrário da ordenação proposta por Alberti, a sua seriação altera a posição relativa das relações aritméticas das consonâncias musicais dado que as áreas grandes trocaram de posição com as áreas pequenas e que a relação entre os números perfeitos 6 e 10 ficou agora intercalada entre as correspondiae inatae.

Os gráficos apresentados nas Figs. 10 e 11 mostram, respetivamente, a ordenação (conforme comparecem no De re aedificatoria) e a seriação (de acordo com as conversões decimais) das relações aritméticas daquelas rationes. Alberti sugere implicitamente uma seriação de valores, desde 1/4, que corresponde a duas oitavas, até à correspondentiae inatae de $\sqrt{ } 4: 1$, apesar de no seu tratado esta sequência não ter sido levada em consideração para ordenar a forma de apresentação destas relações. 
Em síntese, Alberti cobre de forma sistematizada e progressiva a seriação do universo das treze rationes descritas no De re aedificatoria ${ }^{461}$, apesar de as ordenar sequencialmente pelas suas qualidades numéricas como consonâncias musicais, números perfeitos e correspondentiae inatae.

\section{Convergências racionais}

Para finalizar a comparação entre os diferentes sistemas numéricos sugeridos por Alberti, sujeitos a uma mesma linha de base, iremos estabelecer convergências racionais, o que possibilita transformar números irracionais em proporções de inteiros e, consequentemente, comparar numa mesma base comum os diferentes sistemas numéricos utilizados no De re aedificatoria.

A obra Elementa geometriae de Euclides 462 fornece um algoritmo

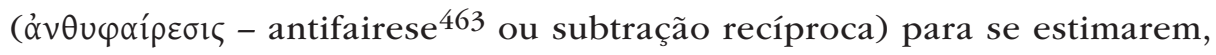
por meio de números inteiros, medidas incomensuráveis, como é o caso de $\sqrt{ } 2: 1$ e $\sqrt{3: 1}$ : "Quando a menor de duas magnitudes desiguais for sucessivamente subtraída da maior e a restante nunca medir a precedente, então as magnitudes serão incomensuráveis" 464 .

461 A rigor trata-se de somente doze rationes dado que os números perfeitos 6 e 10 não são apresentados no De re aedificatoria como um ratio. No entanto, Tavernor mostrou que as proporções de nembos e vãos das faces das capelas laterais do templo de Sant'Andrea, em Mântua, segue rigorosamente esta proporção, bem como as cotas do desenho da igreja de San Sebastiano, em Mântua, elaborado por Antonio Labbaco apresentam igualmente dimensões múltiplas deste ratio. Cf. ROBERT TAVERNOR, Concinnitas in the architectural theory and practice of Leon Battista Alberti, 1985. Tese PhD. Universidade de Cambridge, pp. 24 e 68.

462 EUCLIDES, op. cit., X, 2, 2.

463 A antifairese, derivada do termo grego aphaíresis e do latim aphaeresis, relaciona-se com a ação de separar ou retirar.

464 Seguimos nesta apresentação da antifairese as demonstrações de DAVID FOWLER: "Ratio in Early Greek Mathematics": Bulletin of the American Mathematical Society, Vol. 1, n. 6, November, pp. 807-846; The Mathematic's of Plato's Academy. A New Reconstruction, 2003, Oxford: Oxford University Press, pp. 30-64. 


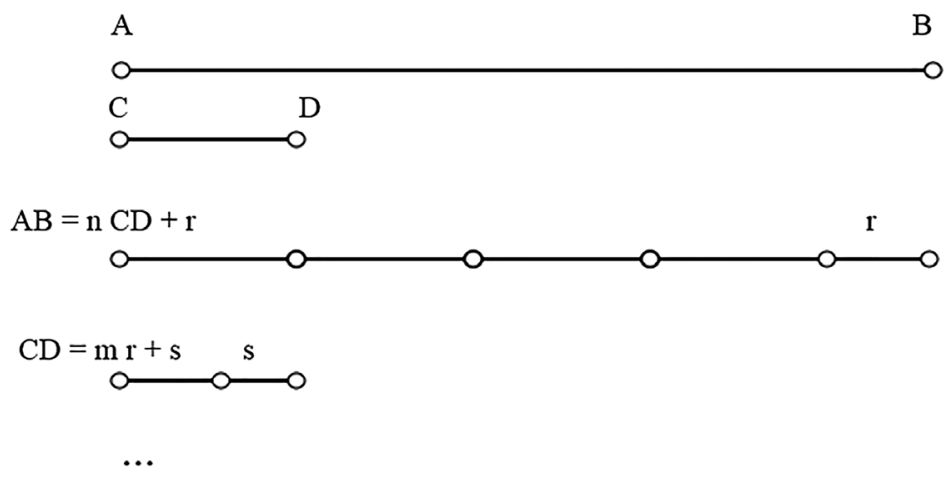

Fig. 12 Antifairese dos segmentos de reta $\mathrm{AB}$ e $\mathrm{CD}$, onde $\mathrm{AB}>\mathrm{CD}, \mathrm{r}$ e s são restos ou diferenças incomensuráveis e $n$ e $m$ são fatores de multiplicação.

Assim, dados dois segmentos de reta $\mathrm{AB}$ e $\mathrm{CD}$, em que $\mathrm{AB}>\mathrm{CD}$, subtrai-se do maior (AB) um múltiplo do menor (n CD), de forma a que a sua diferença ou resto (r) seja inferior à dimensão do menor segmento (CD). Subtraindo continuamente o menor segmento do maior, se o que restar nunca medir exatamente o anterior, as grandezas são incomensuráveis (Fig. 12) 465.

O tratado de Euclides, traduzido por Campano da Novara (1255) e existente na Biblioteca Nazionale Marciana, apresenta profusas anotações, tanto escritas como desenhadas de Alberti, que mostram o perfeito entendimento pelo processo de antifairese ou de subtração recíproca.

Com efeito, ao anotar os Elementa geometriae de Euclides ${ }^{466}$, Alberti faz o seguinte comentário: "detrahatur ex b quotiens potest et sit residuum e"467 (sempre que [a] pode ser removido a partir de b obtém-se um resto e), equivalente no desenho apresentado na Fig. 12 a "sempre que [CD] pode ser removido a partir de $\mathrm{AB}$ obtém-se um resto r". Este

$465 \mathrm{Na}$ contemporaneidade a antifairese é também conhecida por teoria das frações contínuas de números reais maiores que um. Esta enunciação é rejeitada por Fowler ( $o p$. cit., p. 30), dado que a descrição de grandezas incomensuráveis é feita, neste caso, por divisão de números, enquanto na antifairese é realizada, de acordo com o processo sugerido por Euclides, por subtrações repetidas.

466 EUCLIDES, op. cit., X, 2, 69v.

467 Cf. PAOLA MASSALIN - BRANKO MITROVIĆ, op. cit., pp. 172 e 192. 
"pode" significa que se trata de medidas incomensuráveis, como sucede no processo de antifairese para se estimarem as convergências racionais.

A partir de Euclides 468 é possível reconstruir a antifairese para se calcular, de forma aproximada e por rationes de números inteiros, os valores de $\sqrt{2}$ e $\sqrt{3}$.

Sejam p, q, r e s números inteiros e p:q e r:s estimativas de $\sqrt{ } 2: 1$, respetivamente por defeito e por excesso, então $(p+r):(q+s)$ será uma aproximação mais adequada do que qualquer daquelas estimativas anteriores.

Esta antifairese está descrita na Tabela 6 , onde se assume que $\mathrm{p}: \mathrm{q}=1$ é uma estimativa por defeito de $\sqrt{ } 2: 1$ e r:s $=2$ uma aferição por excesso, de que resulta $(\mathrm{p}+\mathrm{r}):(\mathrm{q}+\mathrm{s})=3: 2$, isto é, uma nova estimativa por excesso, dada pela razão da soma de ambos numeradores com a adição dos respetivos denominadores. Na iteração seguinte, o anterior valor de r:s = 2:1 é substituído pela nova estimativa por excesso, isto é, por 3:2, obtendo-se uma nova aferição de 4:3 por defeito. O processo é repetido iterativamente, por soma dos numeradores e denominadores das rationes e da sua substituição, seja por excesso, seja por defeito, até ao grau de precisão desejada, de forma a se representar $\sqrt{ } 2: 1$ exclusivamente por números racionais.

\begin{tabular}{cccc}
$\begin{array}{c}\mathrm{p}: \mathrm{q} \\
\text { defeito }\end{array}$ & $\begin{array}{c}\mathrm{r}: \mathrm{s} \\
\text { excesso }\end{array}$ & $\begin{array}{c}(\mathrm{p}+\mathrm{r}):(\mathrm{q}+\mathrm{s}) \\
\text { defeito }\end{array}$ & excesso \\
\hline $1: 1$ & $2: 1$ & & $3: 2$ \\
$1: 1$ & $3: 2$ & $4: 3$ & \\
$4: 3$ & $3: 2$ & $7: 5$ & $10: 7$ \\
$7: 5$ & $3: 2$ & & $17: 12$ \\
$7: 5$ & $10: 7$ & & \\
$\ldots$ & & & \\
\hline
\end{tabular}

Tabela 6 Processo de antifairese para se obter uma aproximação de $\sqrt{ } 2: 1$ exclusivamente por números racionais ${ }^{469}$.

468 EUCLIDES, op.cit., X, Caps. 2, 3 e 4 .

469 Cf. DAVID FOWLER, op. cit., p. 824. 
A Fig. 13 mostra graficamente o processo de aproximação, baseado na antifairese, para se obter uma convergência racional que represente o número $\sqrt{ } 2$, a partir dos números inteiros 1 e 2 , respetivamente por defeito e por excesso.

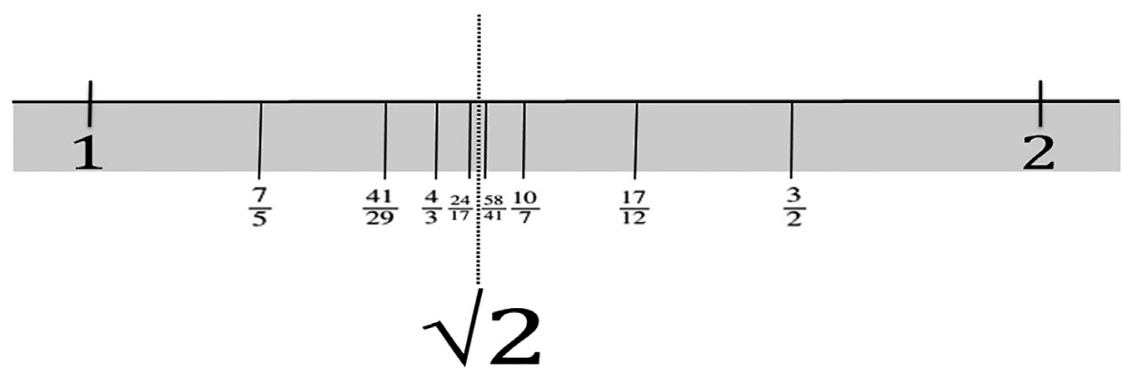

Fig. 13 Processo de aproximação sucessiva, por antifairese, para se obter uma representação de $\sqrt{ } 2$ por números racionais.

A problemática que agora se coloca é saber qual o limite para, no âmbito do De re aedificatoria, prosseguirmos esta convergência racional para $\sqrt{2}$ :1. Com efeito, se observarmos a Tabela 7 , podemos constatar que o processo de convergência pode continuar indefinidamente ${ }^{470}$.

$\begin{array}{rrrrrr}1: 1 & \mathbf{3 : 2} & \mathbf{7 : 5} & 17: 12 & 41: 29 & \ldots \\ 2: 1 & \mathbf{4 : 3} & \mathbf{1 0 : 7} & 24: 17 & \mathbf{5 8 : 4 1} & \ldots\end{array}$

Tabela 7 Convergências racionais para $\sqrt{2}$ :1. A negrito as convergências com numeração igual ou inferior a 16 .

A primeira questão a atender é verificar que convergências são aceitáveis no âmbito do De re aedificatoria, dado que Alberti não utiliza, nos diferentes sistemas descritos, números com valores superiores a 16 unidades. Consequentemente, descartamos as convergências racionais

470 Cf. DAVID FOWLER, op. cit., pp. 41-51. 
que utilizam numeração com valores superiores (Tabela 7), o que significa que estamos em conformidade com a noção de número dada por Nicómaco de Gerasa ${ }^{471}$ como uma multiplicidade limitada que se gera entre dois extremos.

Para os restantes casos, aceitáveis dentro destes limites, podemos constatar que a convergência 10:7 =1,4185 ... é a que apresenta menor discrepância em relação ao valor de $\sqrt{ } 2=1,4142 \ldots$, isto é, uma diferença de apenas $0,0043 \ldots$, pelo que será a estimativa mais adequada para representar aquele número irracional.

\begin{tabular}{rrrrrrll}
\hline $1: 1$ & $\mathbf{2 : 1}$ & $\mathbf{5 : 3}$ & $\mathbf{7 : 4}$ & $\mathbf{1 9 : 1 1}$ & $26: 15$ & $71: 41$ & $\ldots$ \\
$3: 1$ & $\mathbf{3 : 2}$ & $\mathbf{9 : 5}$ & $\mathbf{1 2 : 7}$ & $33: 19$ & $45: 26$ & $\mathbf{1 2 3 : 7 1}$ & $\ldots$ \\
\hline
\end{tabular}

Tabela 8 Convergências racionais para $\sqrt{3: 1^{472}}$. A negrito as convergências com numeração igual ou inferior a 16.

De igual modo procedemos para estimar a convergência racional para $\sqrt{3}: 1$ e o resultado mais aproximado é $7: 4=1,75$, dado que é o ratio que apresenta menor discrepância em relação ao valor de $\sqrt{ } 3=1,7320 \ldots$ ou seja, uma diferença de apenas $0,0180 \ldots$, que é sempre menor quando comparada com as restantes convergências (Tabela 8).

Se agora pusermos num gráfico de dispersão os valores dos números inteiros das consonâncias musicais (marcadas a preto), bem como das convergências racionais das correspondentiae inatae (marcadas a cinzento) podemos verificar (Fig. 14) que, tanto num caso como noutro, à medida que o numerador aumenta, também se verifica uma tendência para o denominador progressivamente crescer o que significa, dados os resultados anteriores relativamente à seriação das rationes albertianas, que o sistema de proporções utilizados no De re aedificatoria é relativamente uniforme, pois cobre de forma sistemática e sem hiatos o universo das

471 NICÓMACO DE GERASA, op. cit., II, 1, 2.

472 Idem. 
possíveis relações aritméticas e, por outro, não fomenta discrepâncias entre os valores atribuídos aos numeradores e denominadores daquelas rationes. Por outras palavras, o sistema de proporções albertiano sugere uma concinidade de propósitos para as finalidades com que foi construído, i.e. de estabelecer uma harmonia universal, via sistemas proporcionais, para as formas edificadas.

\section{Denominador}

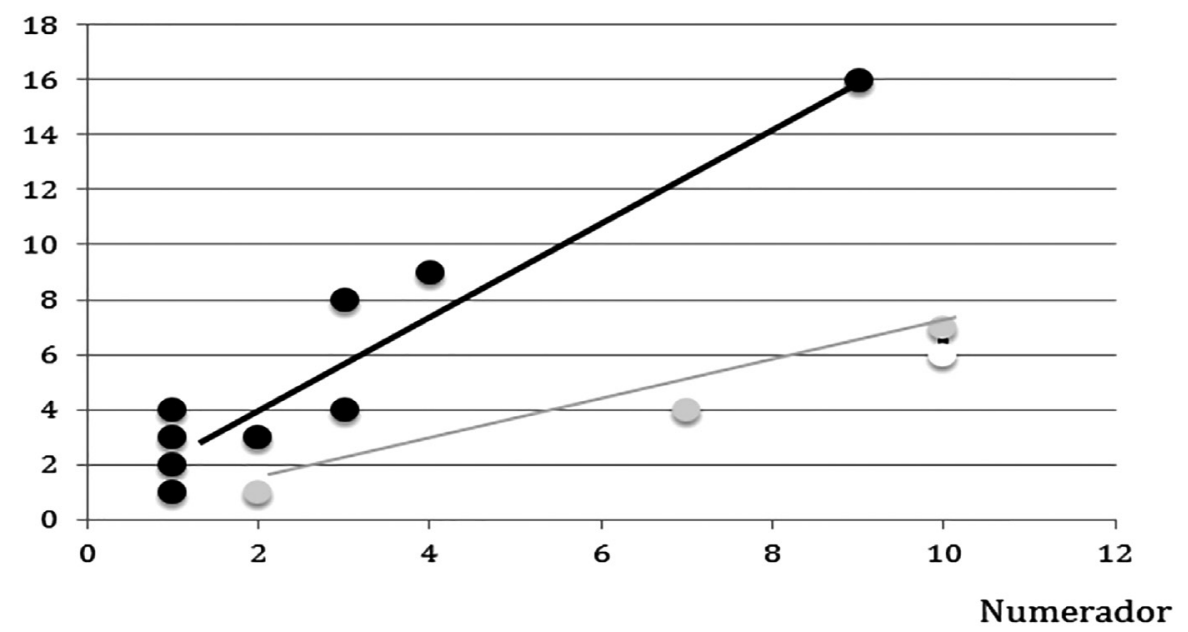

Fig. 14 Gráfico de dispersão dos numeradores e dos denominadores das rationes das consonâncias musicais (a preto), das correspondentiae inatae (a cinzento) e dos números perfeitos (a branco).

No entanto, neste gráfico, o ponto que representa os números perfeitos (marcado a branco) é uma exceção que importa considerar no âmbito dos sistemas proporcionais desenhados por Alberti. Na verdade, os números perfeitos 10 e 6 sugeridos por Alberti ${ }^{473}$ definem uma proporção 5:3, que não faz parte da escala pitagórica.

473 LEON BATTISTA ALBERTI, op. cit., Livro IX, cap. 5. 


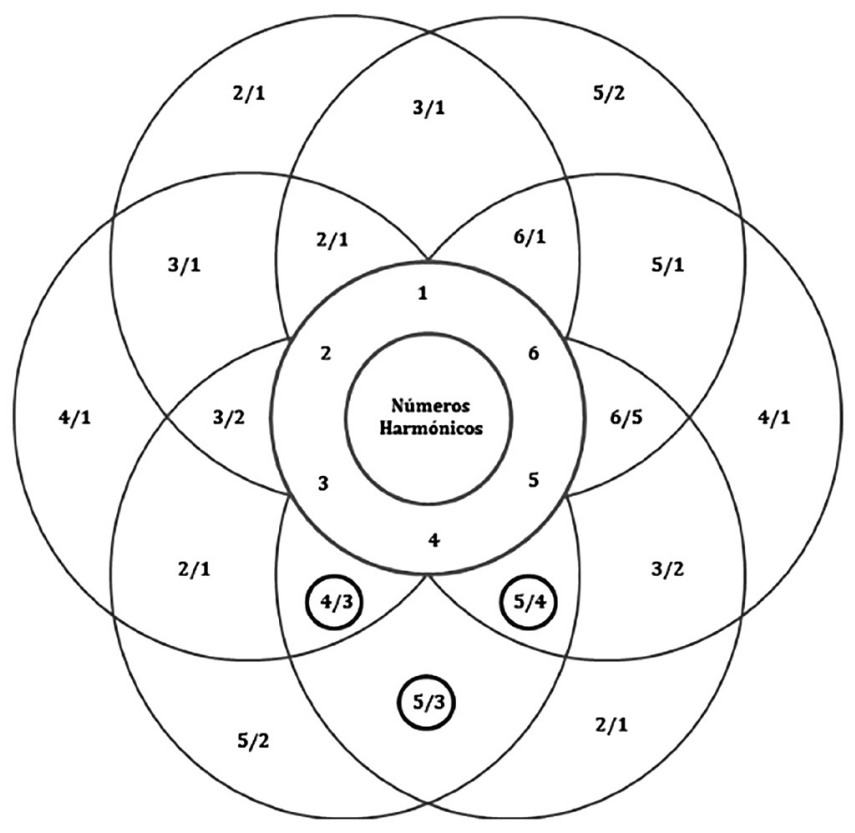

Fig. 15 Ilustração desenhada, para efeitos de legibilidade, a partir do Número Senário in Istutitione Harmoniche, Prima Parte, Cap. 15, de Giosieffo Zarlino, 1588.

Somente com o trabalho de Giosieffo Zarlino ${ }^{474}$ nas Le Istituzioni Armoniche e nos Sopplimenti Musicali é que se começaram a considerar intervalos musicais compostos pelas proporções 3:4:5. Zarlino notou que as consonâncias musicais eram formadas pelos primeiros seis inteiros: a oitava (2:1), a quinta (3:2), a quarta (4:3), a terceira maior e a menor (5:4 e 6:5) e a sexta maior (5:3). Da sexta maior Zarlino refere que é uma consonância composta, dado que entre os seus limites 3 e 5 ocorre o termo médio 4 , i.e. $5: 3=5: 4$ - 4:3. Esta relação é considerada como um intervalo musical composto pelas proporções 3:4:5.

474 GIOSEFFO ZARLINO, Istituzioni armoniche, 1558. Trad. de O. Strunk, in Source Readings in Music History,1950. Nova Iorque: W.W. Norton \& Co.; Idem, Sopplimenti Musicali, cap. 16, p. 34 . Veneza: Francesco dei Franceschi Senese, 1588. 
O Número Senário, conforme concebido por Zarlino (Fig. 15), mostra o universo das harmonias musicais, onde se incluem as relações 5:3, 5:4 e 4:3, construídas a partir dos números harmónicos 1, 2, 3, 4, 5 e 6, dando um sentido global às consonâncias musicais adotadas por Alberti ${ }^{475}$ no De re aedificatoria.

Neste caso, cabe fazer uma referência à citação "Nihil est enim simul et inventium et perfectum" 476 (Nada é ao mesmo tempo novo e perfeito) que remata o Livro III do tratado De pictura, de Alberti ${ }^{477}$, para justificar que "não há arte que não tenha inícios imperfeitos".

\section{Sistemas de numeração e arte edificatória}

A noção de numerus desenvolvida por Alberti tem uma clara implicação na arte edificatória, não se resumindo a uma temática de raízes exclusivamente pitagóricas mas que, para além disso, se apresenta como indispensável na concretização do edificado. Tomemos como exemplo a fachada da igreja de San Sebastiano em Mântua, parcialmente completada em meados de 1470 (Fig. 16).

475 LEON BATTISTA ALBERTI, Ibidem,

476 Cf. MARCUS TULliUS CíCERO, Brutus, Intr., trad. port. e notas de J. S. M. Fernandes. Tese de Mestrado em Literatura Latina. Lisboa: Faculdade de Letras da Universidade de Lisboa, 1987, XVIII, p. 71.

477 LEON BATTISTA ALBERTI, De pictura. Org. de C. Grayson, 1980. Bari: Laterza, III, p. 63. 


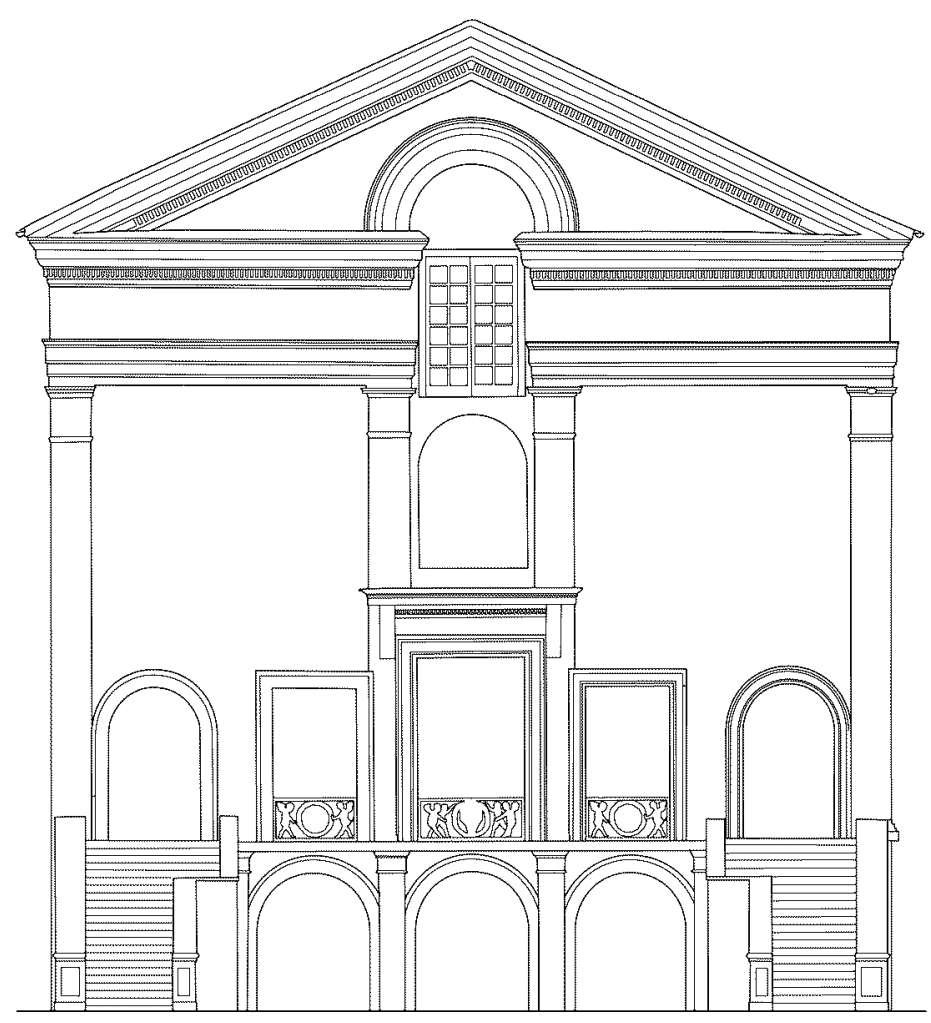

0 12 braccia

Fig. 16 Delineamento da fachada da Igreja de San Sebastiano em Mântua ${ }^{478}$.

478 Reprodução parcial do desenho executado pelo Arq. Bruno Figueiredo, cedido em agosto de 2013 . 


\begin{tabular}{|c|c|c|}
\hline $\begin{array}{c}\text { Dimensões } \\
\mathrm{mm}\end{array}$ & $\begin{array}{c}\text { BroceiaMlantuanas } \\
468 \mathrm{~mm} \\
\end{array}$ & Inteiros \\
\hline 1200 & 2,56 & \\
\hline 1950 & 4,17 & 4 \\
\hline 1525 & 3,25 & \\
\hline 1770 & 3,78 & \\
\hline 1270 & 2,71 & \\
\hline 2260 & 4,83 & 5 \\
\hline 1290 & 2,76 & \\
\hline 1780 & 3,8 & \\
\hline 1560 & 3,33 & \\
\hline 1940 & 4,14 & 4 \\
\hline 1200 & 2,56 & \\
\hline 17745 & 37,92 & 38 \\
\hline 0 & 0 & 0 \\
\hline 1240 & 2,65 & \\
\hline 4660 & 9,96 & 10 \\
\hline 0 & 0 & 0 \\
\hline 600 & 1,28 & \\
\hline 660 & 1,41 & \\
\hline 1920 & 4,1 & 4 \\
\hline 1799 & 3,84 & \\
\hline 2260 & 4,83 & 5 \\
\hline 0 & 0 & \\
\hline 2300 & 491 & 5 \\
\hline 2100 & 4,49 & \\
\hline 2700 & 5,77 & \\
\hline 2100 & 4,49 & \\
\hline 0 & 0 & 0 \\
\hline 3340 & 7,14 & 7 \\
\hline 9460 & 202 & 20 \\
\hline 3330 & 7,11 & 7 \\
\hline 16130 & 34,46 & 34 \\
\hline 0 & 0 & \\
\hline 3370 & 7,2 & 7 \\
\hline 9460 & 20,21 & 20 \\
\hline 3300 & 7,05 & 7 \\
\hline 16130 & 34,46 & 34 \\
\hline 0 & 0 & 0 \\
\hline 192 & 0,41 & \\
\hline 3840 & 8,2 & 8 \\
\hline 2880 & 6,15 & 6 \\
\hline 5080 & 10,85 & \\
\hline 10800 & 23,08 & 23 \\
\hline
\end{tabular}

Tabela 9 Levantamento das dimensões do piso superior da fachada da igreja de San Sebastiano, Mântua, realizado por Tavernor (1985). 
O resultado do escrupuloso levantamento das principais dimensões da parte superior desta fachada foi elaborado por Tavernor ${ }^{479}$ e encontra-se descrito na Tabela 9. Consequentemente, podemos notar que neste levantamento foram utilizados três tipos de medidas: as dimensões lineares em $\mathrm{mm}$, a sua conversão para braccia mantuanas (1 braccio equivale a $486 \mathrm{~mm}$ ) e, por último, uma aproximação, tanto por excesso como por defeito a menos de $5 \%$, a números inteiros.

Podemos verificar, assim, que ocorrem na coluna dos inteiros tanto números pares como ímpares, em quantidades sensivelmente semelhantes, como na coluna das braccia se verifica uma enorme variabilidade de dimensões (Fig. 17), que contrasta com as dimensões dadas pelos números inteiros, aproximados por excesso ou por defeito, que se apresentam somente com $38 \%$ do universo total dos valores levantados (Fig. 18).

Não estamos a sugerir que estas dimensões levantadas por Tavernor seriam as inicialmente cogitadas por Alberti para este edifício do culto religioso que ficou incompleto e sofreu diversas intervenções ao longo dos tempos, a ponto de se considerar que o que resta da conceção original praticamente se resume a pouco mais do que a sua planta.

No entanto, ao inspecionarmos a Tabela 9 podemos verificar que, entre os números inteiros, são passíveis de se estabelecerem, entre outras, as seguintes rationes, subjacentes a uma harmonia universal: $4 / 4=1$ uníssuno; ; $5 / 10=1 / 2$ oitava; $6 / 8=3 / 4$ quarta perfeita; $5 / 4$ terça maior; $10 / 6=5 / 3$ sexta maior (números perfeitos); $6 / 5$ sexta menor; $7 / 4 \approx \sqrt{ } 3$ correspondentiae inatae; $10 / 7 \approx \sqrt{ } 2$ correspondentiae inatae.

479 ROBERT TAVERNOR, Concinnitas in the architectural theory and practice of Leon Battista Alberti, Tese PhD. Universidade de Cambridge, 1985, pp. 396-7. 
Braccia Mantuanas

(levantamento)

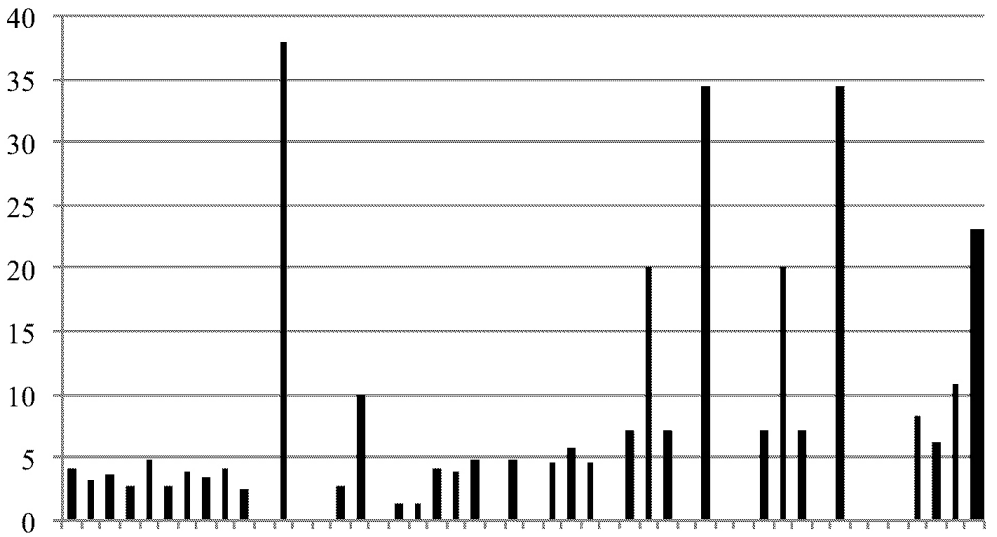

$1133507 \quad 911131517192123252729313335373941434547$

Observações (100\%)

Fig. 17 Levantamento em braccia da fachada da igreja de San Sebastiano, em Mântua.

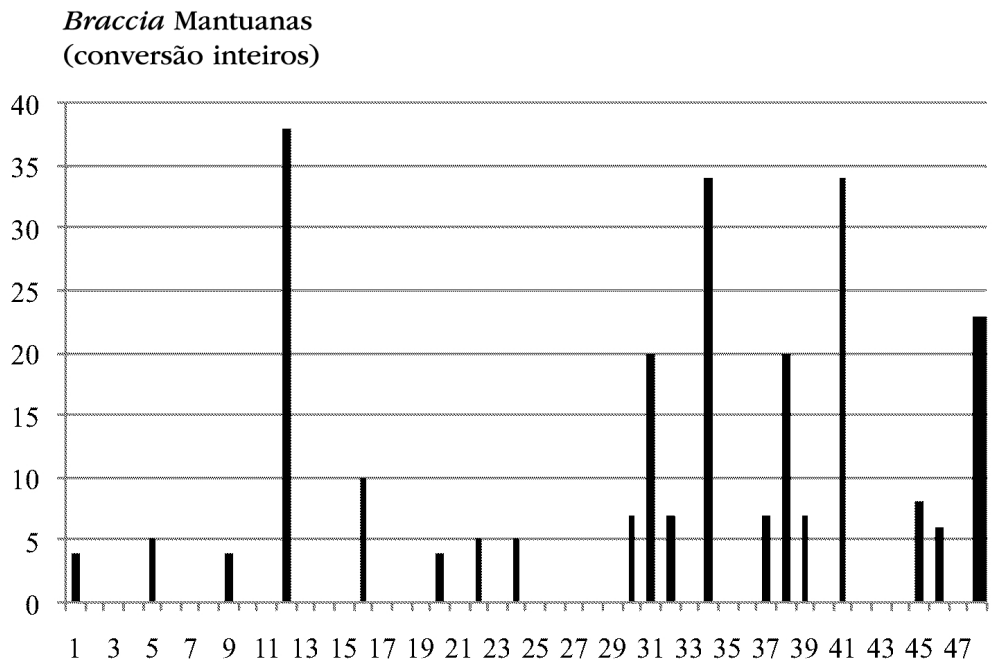

Observações (38\%)

Fig. 18 Levantamento em braccia, aproximado a números inteiros, da fachada da igreja de San Sebastiano, em Mântua. 
Consequentemente, estamos a chamar a atenção para o fato de a maior parte dos sistemas numéricos sugeridos por Alberti no De re aedificatoria, ainda encontrarem acolhida nas suas obras, apesar de aquelas terem sofrido alterações da mais diversa ordem, seja através de números inteiros, seja através de números racionais ou mesmo, se for o caso disso, de números irracionais que, por antifairese, se podem transformar naqueles últimos.

Por outras palavras, o sistema proporcional sugerido por Alberti para a arte edificatória anuncia uma harmonia cósmica como um saber fundado, à semelhança da inaudível música das esferas, no numerus entendido como uma manifestação inteligível da subjacente ordem matemática do universo.

\section{Considerações finais}

O aparente paradoxo, presente na teoria arquitetónica de Alberti, é de como a partir de uma conceção inatista se constrói o processo criativo na conceção em arquitetura, que é constantemente confrontado com as raízes do pensamento clássico sobre a teoria universal da beleza.

Alberti chega mesmo a afirmar que, para a apreciação da beleza, não é a opinião que conta mas uma certa faculdade inata da alma, uma ratio inata, da qual não procura saber qual a sua génese. Com efeito, no Livro IX, cap. 5, Da Arte Edificatória ao discursar sobre quais as razões por que se prefere mais um corpo belo do que outro, afirma: "Não é uma opinião, mas sim um princípio inato no espírito, que fará com que possas emitir um juízo acerca da beleza”.

É neste contexto que Alberti se refere implicitamente aos números poligonais e explicitamente aos números harmónicos, perfeitos e às correspondências inatas (números naturais, inteiros, racionais e algébricos reais), que são hierarquicamente classificados, apresentam rationes seriadas, com termos ordenados, além de terem simultaneamente dimensões:

Quantitativas - cardinais, ordinais, distributivas e adverbiais;

Qualitativas - pares/ímpares; ternário, quaternário, quinário, senário, septenário, octonário e os números nove e dez;

Relacionais - multiplicativas e proporcionais. 
Assim, o conceito de numerus para Alberti ao apresentar dimensões quantitativas, qualitativas e relacionais remete para as categorias de quantidade, qualidade e de relação de Aristóteles ${ }^{480}$, bem como de simultaneidade: "Cada uma das coisas mencionadas em si e por si não constitui nenhuma afirmação, mas pela combinação delas com outras produz-se uma afirmação" ${ }^{481}$.

Esta plasticidade nas possíveis utilizações do conceito de numerus permite a sucessiva requalificação dos sistemas numéricos utilizados na conceção e no projeto edificatório, como um contínuo processo de reflexão em ação conforme assinala Alberti:

"Acerca de mim declaro o seguinte: com muitíssima frequência me ocorreram à mente muitas ideias de obras, que nesse momento me mereciam toda a minha aprovação; ao reduzi-las a linhas, dava-me conta de erros precisamente naquela parte que mais me tinha agradado e que bem precisavam de correção; quando examinei de novo os desenhos e comecei a pô-los em proporção, descobri a minha negligência e censurei-a; finalmente, ao fazê-los à escala e em maquete, sucedeu-me, às vezes, revendo cada um deles, que me apercebi de que me tinha enganado nas contas" 482 .

A sistematização da perfeição do edificado, na qual o conceito de $n u$ merus participa integralmente, seja por meio de consonâncias musicais, seja por números perfeitos, seja por correspondentiae inatae, acaba por ser também um processo mental de natureza construtiva, a que só um método de trabalho, baseado numa constante reflexão em ação na conceção da obra, pode dar resposta: "Grande é o contributo que o tempo traz à execução de todas as obras, fazendo com que repares e reflitas atentamente naquilo que te escapara, por mais perspicaz que sejas" 483 .

480 ARISTÓTELES, Categorias, Porto Editora, Porto, 1995, Caps. VI-VIII.

481 Idem, VI, $2 \mathrm{a}$.

482 LEON BATTISTA ALBERTI, op. cit., Livro IX, cap. 10.

483 LEON BATTISTA ALBERTI, op. cit., Livro IX, cap. 10; Livro II, cap. 1. 
Este tempo apresenta uma dimensão operativa na conceção e na elaboração do projeto, realizada pela ponderada articulação entre o numerus, a finitio e a collocatio, na medida em que a arte edificatória é tempo criador que se converte em desejo pelo delineamento que, ao conformar a matéria, aspira a ser concretizado na plenitude da obra construída.

É neste sentido que, ao apresentar os principais pressupostos no que se refere à construção das primeiras representações numéricas, Ferreira adverte sobre "a importância de se manter o debate sobre o construtivismo e o inatismo enquanto referências epistemológicas na educação matemática" ${ }^{484}$, à semelhança do entendimento que podemos fazer sobre o conceito de numerus em Alberti, anunciador de uma harmonia cósmica que se liberta inicialmente de todas as amarras contextuais e renasce, nos seus princípios fundamentais, ao ser concretizado na arte edificatória.

Nota Final: Este trabalho é resultante do projeto de investigação "Digital Alberti", desenvolvido no Centro de Estudos Sociais da Universidade de Coimbra e financiado pela Fundação para a Ciência e Tecnologia (FCT), no âmbito do COMPETE/FEDER, Portugal (PTDC/AUR - AQI/108274/2008).

484 MARIA DE CONCEIÇÃO RODRIGUES FERREIRA, A construção do número: a controvérsia construtivismo-inatismo, São Paulo, Educ. Mat. Pesqui., 2008, v. 10, n. 2, p. 247. 